INCORPORATING SUCCESSFUL BLACK AND LATINX STUDENT VOICE AT SUBURBAN SCHOOLS: WHITE PRINCIPALS AS ANTI-RACIST LEADERS

\author{
A dissertation submitted to the faculty of \\ As \\ 35 \\ 2017 \\ EDD \\ - C53 \\ San Francisco State University \\ In partial fulfillment of \\ The Requirements for \\ The Degree \\ Doctor of Education \\ In \\ Educational Leadership
}

by

Heather Michele Clary-Wheeler

San Francisco, California

May 2017 
Copyright by

Heather Michele Clary-Wheeler 2017 


\section{CERTIFICATION OF APPROVAL}

I certify that I have read Incorporating Successful Black and Latinx Student Voice in Suburban Schools: White Principals as Anti-racist Leaders by Heather M. Clary-Wheeler, and that in my opinion this work meets the criteria for approving a dissertation submitted in partial fulfillment of the requirements for the degree: Doctor of Education in Educational Leadership at San Francisco State University.

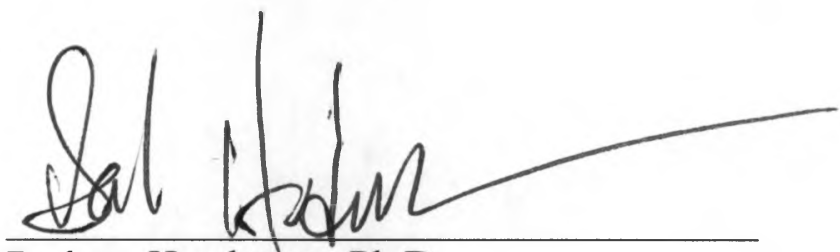

Barbara Henderson, Ph.D.

Interim Director

Doctoral Program in Educational Leadership

Professor of Education

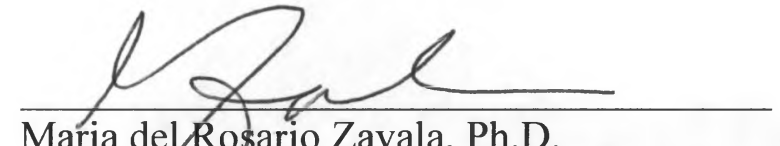

Maria delRosario Zavala, Ph.D.

Assistant Professor

Elementary Education

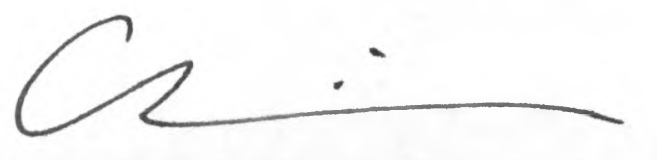

Christopher Kolar, M.S.Ed

Director, Research, Assessment, and Evaluation PAUSD 


\title{
INCORPORATING SUCCESSFUL BLACK AND LATINX STUDENT VOICE AT SUBURBAN SCHOOLS: WHITE PRINCIPALS AS ANTI-RACIST LEADERS
}

\author{
Heather M. Clary-Wheeler \\ San Francisco State University \\ 2017
}

Within suburban schools, the educational experiences of Black and Latinx students are racialized because achievement is defined as the appropriate domain of White or Asian students. Classifying the academic success of a Black and Latinx student as unusual leads to marginalization and limited support for these underrepresented students within predominately White and Asian suburban schools. This study is grounded on the assumption that Students of Color are successful, and that their success is reproducible. At the same time, it seeks to uncover the tremendous amount of effort that students have invested in being academically successful, despite societal and school-based obstacles. Using a qualitative study design, 16 Black and Latinx students who were identified as academically successful participated in up to two rounds of focus group interviews. A Critical Race Theory (CRT) lens made central the voice of the students in the data collection and analysis. The concept of figured worlds (Holland, Lachicotte, Skinner, \& Cain, 1998) provided the theoretical frame to analyze their narratives about the high-pressured, racialized school environment and some of the causes and coping mechanisms they used. Culturally Responsive School Leadership (Khalifa, Gooden, \& Davis, 2016) served as a practical foundation for understanding how school leaders in a racialized school can begin to approach reforming site systems and practices with the goal of supporting all students equitably. Recommendations for school leaders include making connections to underrepresented families and community members a priority. Additionally, further recommendations focus on ways to develop and sustain a culturally responsive school, classroom, and instructional focus. Finally, attention is given to ways an anti-racist school leader, especially a White leader, can use critical reflection on their own internal biases as a starting point to infuse critical discussions about race into everyday conversations with the school community.

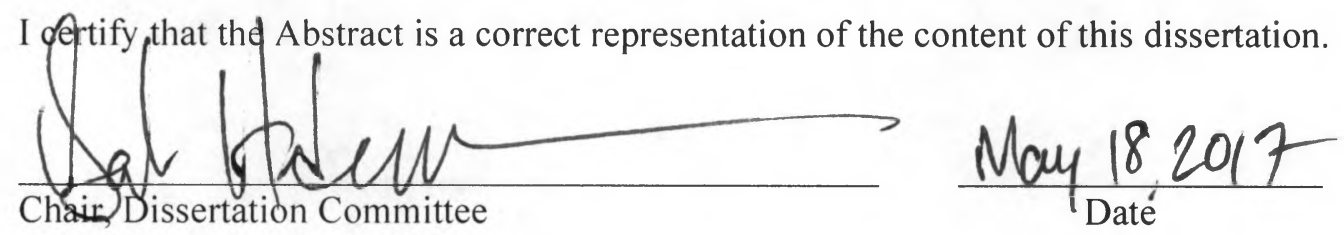




\section{ACKNOWLEDGEMENTS}

To my husband, best friend, and partner, Kyle: There are not enough words to properly thank you for being my greatest advocate, inspiration, and steadfast support throughout this program. With you, all things are possible.

To my children, Noelle and Jackson: You make me want to be a better person. For you, I strive to be someone you are proud to call your mother. I love you with all my heart.

To my parents, Michael, Donna, and Marye, and grandmother, Dorothy: You instilled in me a love for education and showed me by example the importance of life-long learning. Your unwavering belief in me has been the foundation on which I have built my life's work.

To chair, Barbara: You rock! You were relentless in your expectations and equally relentless in your support.

To my committee, Maria and Chris: You rock, too! Your amazing insights and expertise shaped my work in ways I am only beginning to realize.

To my fellow musketeer, Janelle: Together, we made it!

To my students: I am awed every day by your vision and insights. You inspire me with your resilience and determination to achieve success on your own terms. I am so appreciative of your willingness to share your world with me. You are my why. 


\section{TABLE OF CONTENTS}

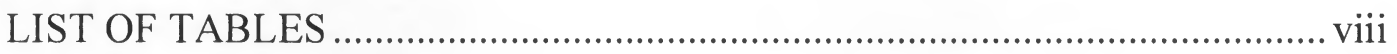

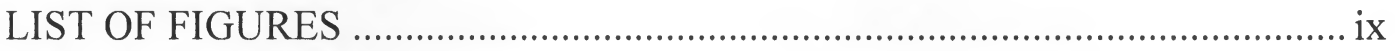

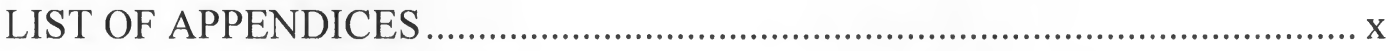

Chapter One: Introduction .............................................................................. 1

Purpose of Study ............................................................................................ 4

Conceptual Framework: Figured Worlds....................................................... 7

Agency and Figured Worlds ................................................................. 9

Racism within Figured Worlds ................................................................ 11

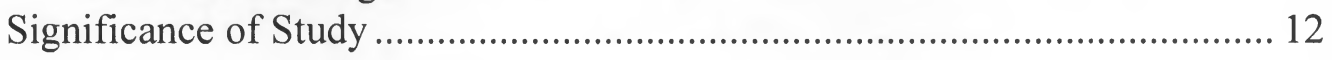

Chapter Two: Literature Review..................................................................... 14

Educational Inequities and Critical Race Theory ............................................. 15

Racialized Climate of Suburban Schools ..................................................... 18

Student Responses to Racialized Educational Experiences .............................. 24

Culturally Responsive School Leadership ................................................... 28

Critical Self-reflection........................................................................ 29

Developing Culturally Responsive School Teachers and Curriculum...... 30

Promoting Culturally Responsive and Inclusive School Environments ...................................................................................... 32

Engaging Students and Parents in Community Contexts.......................... 33

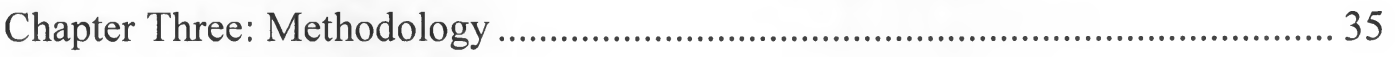

Critical Race Methodology ........................................................................ 35

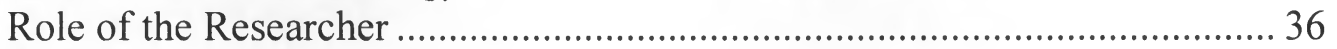

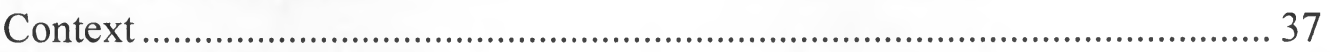

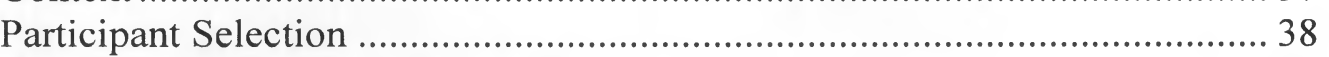

Ethics and Protection of Human Subjects....................................................... 41

Data Collection ...................................................................................... 41

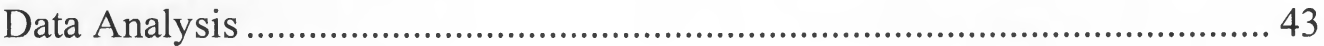

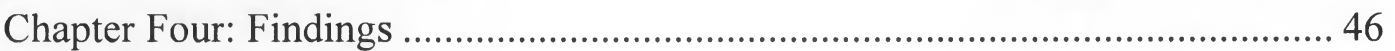

Figured Worlds Framework ........................................................................ 47

Cultural Artifacts.................................................................................. 48

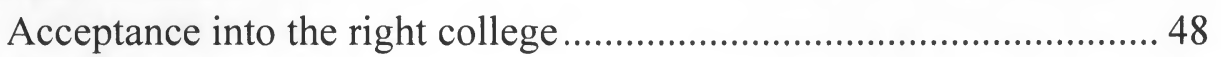

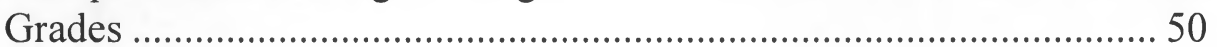




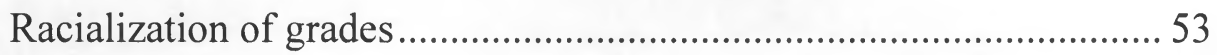

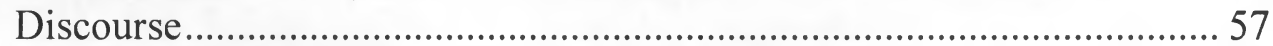

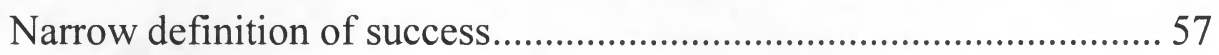

Hiding failure ………………………............................................... 58

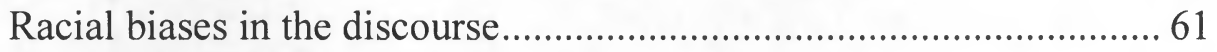

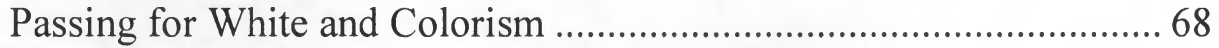

Microaggressions, racist jokes, and racist language ………………...... 70

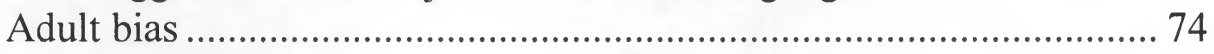

Identity/World Making .......................................................................... 78

Pride in themselves and their racial/cultural identity ........................... 78

Proving them wrong.................................................................... 80

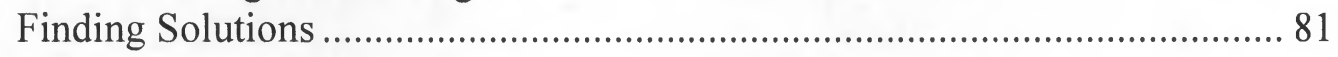

Chapter Five: Discussion and Conclusions......................................................... 89

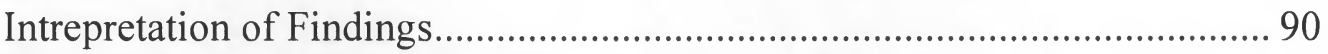

Implications, Significance, and Praxis ………………………....................... 92

Culturally Responsive School Leadership ................................................. 93

Engaging Students and Parents in Community Contexts..................... 94

Community connection recommendations......................................... 96

Promoting Culturally Responsive and Inclusive School

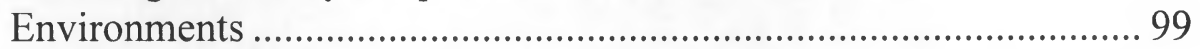

School culture recommendations .................................................. 100

Developing Culturally Responsive School Teachers and

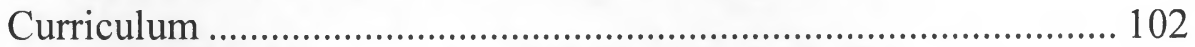

Culturally Responsive Education recommendations ..................... 104

Critical Self-reflection.................................................................... 107

Critical Self-reflection recommendations ..................................... 109

Recommendations for Further Study ....................................................... 111

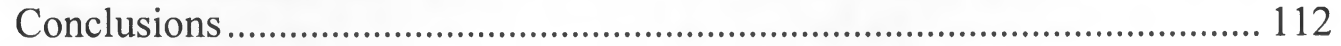

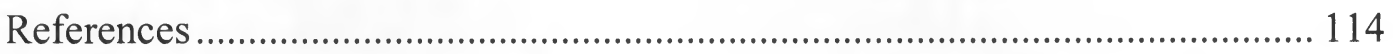

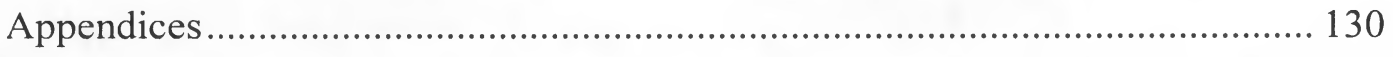




\section{LIST OF TABLES}

Table

Page

1. Student Participation Demographics 40

2. Engaging Students and Parents in Community Contexts ............................. 96

3. Promoting Culturally Responsive/Inclusive School Environments .............. 99

4. Developing Culturally Responsive School Teacher and Curriculum .......... 103

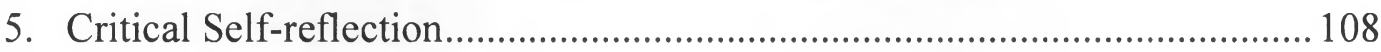




\section{LIST OF FIGURES}

Figure

Page

1. Student's authorship within the Figured World of Academic Success ........... 10 


\section{LIST OF APPENDICES}

Appendix

Page

A. Student Interview Protocol ........................................................................ 130

B. Recommendations for Action (Praxis) ................................................... 133 


\section{Chapter One: Introduction}

Within suburban schools, the educational experiences of Black and Latinx ${ }^{1}$ students are racialized due to achievement being seen as the domain of only certain ethnicities, usually White or Asian. Therefore, the success of a Black or Latinx student is viewed as unusual, not an expected outcome. This leads to marginalization and limited support for the success of Black and Latinx students within predominately White and Asian suburban schools (Allen \& Griffin, 2006; Ispa-Landa \& Conwell, 2015; McKown \& Weinstein, 2008). For example, Black and Latinx students have a greater likelihood of being inequitably denied entrance into rigorous, college- preparatory classes, even when they score similarly to their White and Asian counterparts on standardized tests (Childress, Doyle \& Thomas, 2009; Darling-Hammond, 2010; Geiser \& Santelices, 2004; Oakes, 2005).

Furthermore, the disproportionately low achievement of Black and Latinx students within highly-resourced suburban schools has been brought to the forefront by the recent federal mandates to track and report student achievement in a variety of categories, including race and ethnicity. Motivated by the public display of this disaggregated data, which illuminates stark differences in educational outcomes

1 In this study, Black is the descriptor chosen an acknowledgement that individuals who identify as Black have ancestors from all over the world. Latinx is a regionally-preferred ethnic term and will be used as a non-binary gender-neutral descriptor. In either case, the descriptor chosen by the students will not be altered. 
within their schools, as well as the data's impact on funding, districts are working to uncover the contributing factors and provide better supports for underachieving minority students (Chapman, 2013).

Golden Valley Unified School District (GVUSD) is one such highachieving, affluent suburban district in Northern California that has begun to take action. GVUSD has responded to this dilemma by commissioning an advisory committee to investigate the root causes of the academic achievement inequities within their district and report back to their Board of Education with recommendations to address them. During the 2014-2015 school year, the Diversity Development Advisory Committee (DDAC) met twelve times over the course of six months. It gathered research through a variety of methods, including standardized test scores, college-prep course completion, district-wide surveys, interviews with stakeholders, school site visits, and a series of focus groups with students, parents, teachers, administrators, and community members. Through this process, the DDAC identified five key problem areas (PA), together with short- and long-term recommendations for addressing the PAs. The recommendations were then developed using findings from relevant empirical articles and visits to sites outside of the district where promising practices were in place.

In analyzing Golden Valley Unified School District, it is helpful to look at the location and demographics. GVUSD is a suburban district located between two 
large metropolitan areas and serves about 12,000 students. GVUSD consists of two comprehensive high schools (9-12), three middle schools (6-8), and twelve elementary schools (K-5), as well as a preschool, adult school, and a hospital school in conjunction with a local children's hospital. Within this affluent area, the mean household income of the community stands at $\$ 163,661$, with just $8.5 \%$ of the students qualifying for free and reduced lunch, compared to $38.9 \%$ in the surrounding area. Additionally, the community is highly educated, having $79 \%$ of the adult population who hold at least a four-year college degree. The majority of the students attending schools in GVUSD are White (43.9\%) and Asian (33.9\%), with Black and Latinx students comprising just $2.3 \%$ and $11.2 \%$, respectively. Overall, GVUSD students score in the fifth percentile on national standardized exams and $85 \%$ of the student body go on to four-year universities after graduation. After examining all the information collected, the DDAC discovered that Black and Latinx students did significantly worse than Whites and Asians, and students from low-socioeconomic families scored lower than affluent students. These results seemed to underscore the need to provide under-resourced students with enrichment opportunities that their families cannot afford. However, when the committee dug deeper, it was surprised to learn that the difference in performance persisted for Black and Latinx students who came from affluent, highly educated 
families. This outcome reflects national data that has shown that while socioeconomic status does play a part in low school success, systemic inequities created by racial prejudices have a larger effect on student outcomes. Simply stated, Latinx and Black students do far worse in school than their White and Asian counterparts, no matter the socioeconomic level or family background (DarlingHammond, 2013; Oakes, 2005; Smith, 2005; Steinberg \& Almeida, 2008).

The DDAC's report to the Board of Education made it clear that placing the focus on a so-called "achievement gap" was problematic because the student then becomes the cause of the issue, ignoring the systemic inequities created by racial biases which act upon the students (Bernal, 2002; Jayakumar, Vue, \& Allen, 2013; Ladson-Billings \& Tate, 1995; Solórzano \& Yosso, 2002). Instead, the DDAC framed the issue as an "opportunity gap" so as to bring attention to the disparate chances Black and Latinx students within GVUSD have to access rigorous and meaningful educational experiences (Irizarry, 2015; Mayfield \& Garrison-Wade, 2015; Olszewski-Kubilius \& Clarenbach, 2014).

\section{Purpose of the Study}

As a school site leader at Creekside High School (CSHS), one of two high schools within the Golden Valley Unified School District, I feel a particular obligation to address the systemic barriers faced by my underrepresented students. 
Further, as an anti-racist leader, my first endeavor is to disrupt the inequitable practices and systems within schools, and then to remove the barriers that disenfranchise students, replacing them with new systems that operate equitably (Khalifa, Gooden, \& Davis, 2016; Theoharis \& Haddix, 2011). However, as a White educator, I struggle with my own privilege and world-view, especially in how I can reimagine the current biased systems at play within the school. This attention to my own bias is what led me to the realization that the work I strive to accomplish on behalf of the marginalized students in my school necessitates their involvement (Khalifa, et al., 2016; Picower, 2009).

Therefore, building upon the DDAC's findings and framework that the ongoing lack of achievement for Black and Latinx students in GVUSD is a result of an "opportunity gap" created by racially-biased systemic inequities, this study was conducted to better understand the educational experiences of Black and Latinx students in the school at which I am a site leader. Specifically, this qualitative exploration of the experiences of Black and Latinx students who are academically successful at my high school serves to highlight the strategies and resources used by the students to overcome the obstacles they face due to systemic racial inequities. Within focus groups comprised of similarly successful students at CSHS, the discussions dove into their thoughts on what defines success, generally 
and academically, and how they attained it. Moreover, the conversations included their experiences with race and racism in their school careers, especially at CSHS.

By privileging the voices of the students who are experiencing the racially charged learning environment at CSHS and are nevertheless performing academically, this study illustrates the factors that support Black and Latinx students in achieving success. Asking students to participate in such a study inherently comes from a place of affirmation, rather than a deficit. Starting with the assumption that historically underrepresented students are successful, and that success is reproducible, amplifies the tremendous amount of effort students have put into being academically successful despite the societal and school-based obstacles they have encountered. Rather than ask why Black and Latinx students at CSHS are not successful, this study seeks to turn that question around and approach the student experiences from an anti-deficit lens (Harper, 2015).

From there, anti-racist educational leaders can learn from the recommendations offered here to identify factors that are under their purview within the school structure to be able to support all students equitably. The research question that drove this qualitative investigation was: What are the experiences of successful Black and Latinx students at a high-achieving, predominantly White and Asian suburban high school? 


\section{Conceptual Framework: Figured Worlds}

Figured worlds, a conceptual framework developed by Holland, Lachicotte, Skinner, and Cain (1998) offers an insight for examining the complexity of educational experiences that influence Black and Latinx students at a highachieving high school that too often associates achievement with being White. Holland et al. defined a figured world as the parameters that guide the actions of individuals within a particular environment or situation. While not entirely deterministic, a figured world is created through social interactions that work to structure and order individuals. At the same time, it is the sum of activities that people take part in that builds and generates what it means for them to be a part of that environment (Hatt, 2007; Urrieta, 2007a; Saunders, 2012; Esmonde, 2014; Barron, 2014; Ryu, 2015). In the world of academic success at CSHS, the students, teachers, staff, and community members at the school are all interacting with each other in ways that give meaning, definition, and value to each individual.

Three key features provide the basic structure of figured worlds: cultural artifacts, discourse, and identity (Holland et al., 1998). Cultural artifacts are used to enact the roles assigned to or assumed by individuals within the figured world. Whether tangible or conceptual, artifacts are utilized by individuals to position themselves within the world and signal their position to others. For example, an 
artifact can be the lanyard and badge that a school employee wears, or a bit more abstractly, it can be the job they possess as campus security or teacher. The artifact not only influences how a person feels and responds when interacting with it, but it effects how others within the figured world feel and interact with them, as well. It is through this interacting with others that the artifact takes on meaning. It is especially through the discourse about the artifact that members of the figured worlds establish this meaning. In other words, how the individual and others talk about the artifacts, including any emotions or opinions expressed, infuses meaning into the artifact that is then transferred onto the people connected to it (Holland et al., 1998). When discussing the job of campus supervisor as one with the power to give or take permission to attend an event, the students not only define and give authority to the job (artifact) itself, but to the individual with that job. Thus, the discourse influences how the students feel and act towards the job of campus supervisor, as well as how the individual holding the job feels and acts towards the students.

This discourse about the artifacts also helps to define the identity of individuals involved, through the use of positionality, space of authoring, and world making (Holland et al., 1998; Seglem \& Garcia, 2015). Individuals form their identity as they begin to comprehend the influence and position of the roles they 
have or might take. In addition, their identity is shaped by the way others treat them in the roles they take on. As an individual grasps and takes hold of this positionality, they are able to move into a space of authoring where deliberate decisions can be made. This can lead to the prospect of world making, where individuals are capable of actively shaping their world and, thus, their own identity (Holland et al., 1998; Seglem \& Garcia, 2015).

Agency and Figured Worlds. This interplay of perception, action, and relationships forms the figured world of academic success that is socially created and dynamic, where students are sorted and given roles based on a host of factors (Holland et al., 1998; Hatt, 2007; Urrieta, 2007a, 2007b; Saunders, 2012; Esmonde, 2014; Barron, 2014; Ryu, 2015; Seglem \& Garcia, 2015). Students have the ability to navigate their role within this world of academic success in a variety ways, from acceptance to rejection to negotiation, even flat-out ignoring their given role (Barron, 2014). Holland et al. (1998) call this the space of authoring because a proscribed role must be responded to, although the individual determines exactly how to respond.

The conceptual model below (figure 1) illuminates the agency of the student as they endeavor to navigate the many elements within the school environment. The individual student at CSHS (represented by the small light circle in the middle) has 


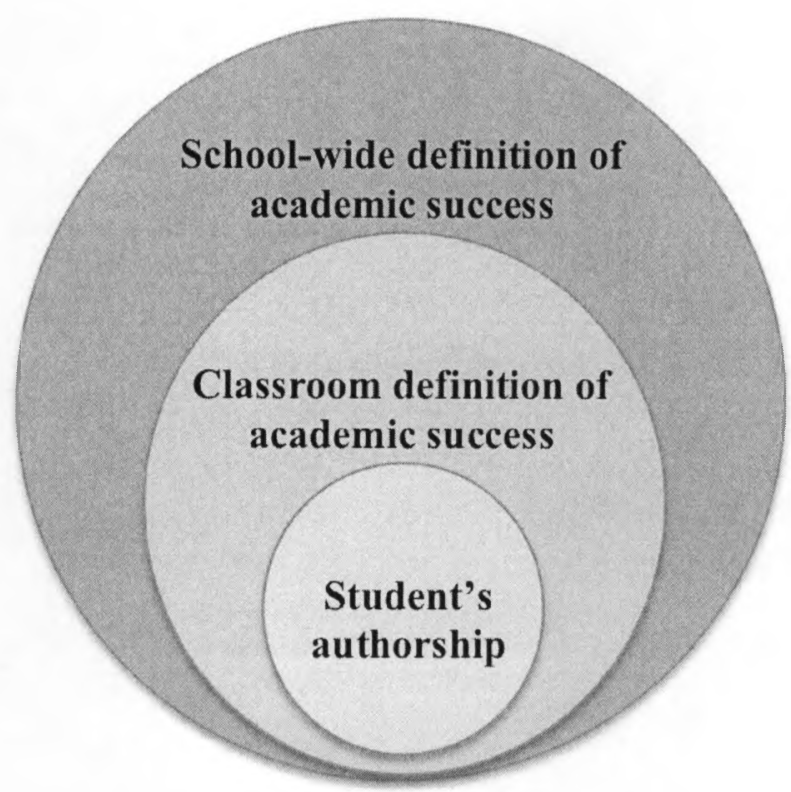

Figure 1. Student's authorship within the Figured World of Academic Success the power (agency), to shape their role within the school, but must do so through interaction with others, including students, teachers, administrators, and staff members (Hatt, 2007; Saunders, 2012; Barron, 2014). Students must also interact with the artifacts of this figured world of academic success, such as the curriculum being taught or the literature and textbooks used to teach the curriculum. Further symbols of academic success can take the form of grades, standardized test scores, and being in one of the higher-level classes. Another factor is the prevailing discourse about the artifacts, such as how to look and act like a successful student and the particular vernacular used by teachers and other students to further describe the artifacts. This prevailing discourses functions to limit the access of certain 
students to particular kinds of identities, while encouraging others to take on those same identities. A student's positionality within the figured world would shape whether they viewed the discourse as a hindrance or an advantage (Urrieta, 2007a; Hatt, 2007). All of these factors are represented in the model by the larger circles around the student, school-wide and classroom definitions of success.

Racism within Figured Worlds. Within CSHS, White norms and privileges are viewed the prevailing standard, which is an illustration of dysconscious racism (King, 1991; Gordon, 2012), a type of racism so widespread that other groups seen as excelling in academics are inextricably linked to White success. Thus, due to their high academic success, Asian students at CSHS are associated with the notion of White success (O’Connor, Mueller, Lewis, Rivas-Drake, \& Rosenberg, 2011; Muller, Riegle-Crumb, Schiller, Wilkinson, \& Frank, 2010; Nunn, 2011). In the culture of CSHS, the concept of success is symbolized by which students are allowed to represent the student body in various capacities, including being put on student leadership committees or elected to student council, being in the school spirit videos produced by the student council, or being allowed to sit in the seats of the more rigorous classes at the school. Everyday racist occurrences reinforce the racism with the figured world of academic success at CSHS, leading all the students to expect that White and Asian students will take higher-level classes and go on to 
four-year universities. In contrast, the academic futures of Black and Latinx students are perceived as being much more limited (Hatt, 2007).

Furthermore, while students have the agency to choose their response to a role given to them by the figured world in which they find themselves, they must deal with the part that the artifact plays, which is often that of blockade (Hatt, 2007). When an artifact, such as grades or the commonly believed discourse about how an academically successful student should look or act, begins to limit access for certain students to certain educational experiences, it becomes a structural barrier. In this way, artifacts form and influence the way students view their own, and others' ability to be academically successful (Urrieta, 2007a). For example, when grades are used to filter which students can enroll in a particular class, the grades then act as barricades intended to maintain the scarcity of seats available in that course. These barriers have been so thoroughly imbued with the dysconscious racism within the system that they replicate the status quo, only allowing in those students meeting the appropriate definitions of the "right student" (Hatt, 2007). At CSHS, the "right students" are overwhelmingly White and Asian students.

\section{Significance of Study}

A study of the experiences of successful Black and Latinx students in a majority White and Asian suburban high school is an important first step in 
developing school practices that directly support the principle of equal access that our democratic society is founded upon. Moreover, this study expressly upholds the stated goal of public schools to ensure college and career readiness for every student. The iterative nature of the figured world of academic success at CSHS makes it impossible to reach for an easy fix or simple intervention. However, uncovering the strategies and supports used by students to overcome structural inequities allows anti-racist educators to build on and expand these tactics within the school studied, while providing leaders in similar school settings a blueprint that they can apply to their own school. Additionally, action cannot be taken without first inviting the affected students into the dialogue about possible solutions and adjustments to the structural barriers within the school. Student experience is central to the purpose of schools, yet their opinions, knowledge, thoughts, and feelings are often ignored (Friend \& Caruthers, 2012). Intentionally positioning student voice as the starting point for structural development, rather than simply the recipient of a pre-determined policy established by the adults in charge, creates a dynamic where the experiences of marginalized individuals can begin to drive the institution intended to support their growth. This study can serve as an example of one way to build from the source, rather than impose and implement from the outside. 


\section{Chapter Two: Literature Review}

With race strongly impacting how students interact and are "figured" by others within the figured world of academic success at Creekside High School, this chapter begins with a discussion of Critical Race Theory (CRT) to highlight the effect on academic achievement that race has in schools perpetuating the predictive power of demographics and White privilege, as well as explore some of the manifestations of racism students face. The next section of the literature discusses how the school environment racializes academic endeavors for Black and Latinx students, especially in predominately White and Asian suburban high schools such as Creekside. The third section addresses how the racialized nature of education within these suburban schools leads to varied responses from Black and Latinx students as they navigate their roles. Finally, I argue that in such schools, educational leaders have a particular responsibility to stop racist practices, while also actively creating systems that equitably educate all students. Just as CRT serves as the philosophical basis for this activist stance, Culturally Responsive School Leadership (Khalifa, et al., 2016) serves as a practical foundation for understanding how school leaders in a racialized school can begin to approach reforming site systems and practices, and therefore provides the final section of this chapter. 


\section{Educational Inequities and Critical Race Theory}

Critical Race Theory (CRT) offers a perspective from which to view the inequitable outcomes experienced by Black and Latinx students in a majority White and Asian Suburban high school. Solórzano and Bernal (2001) identified the following five central CRT tenets: 1) placing race and racism as a centerpiece that intersects with other forms of discrimination; 2) challenging all manifestations of dominance, including such ideas as neutrality, meritocracy, and colorblindness, among others; 3 ) undertaking a social justice pledge; 4) legitimatizing and focusing on the experiences of people of Color; and 5) utilizing a multi-disciplinarian point of view. CRT contends that racism is an everyday, commonplace occurrence that permeates the lives of people of Color, making it hard to eliminate any but the very flagrant examples of racism and bias (Delgado \& Stefancic, 2001). Many school experiences of Black and Latinx students fall into this "ordinary" trap because bias is woven into the daily fabric of their school lives. For example, studies have shown that, beginning at the elementary level, Students of Color continue to have a greater likelihood of being placed (or tracked) into less rigorous classes despite having comparable standardized test scores (Darling-Hammond, 2010; Oakes, 2005). Due to the persistently rigid nature of tracking, Black and Latinx students are disproportionately stopped from entering classes in high school that would prepare 
them for college and jobs with higher earning potential (Childress, et al., 2009; Geiser \& Santelices, 2004).

Racism represents a tool by which those in power limit access to resources, such as knowledge and eventual economic gain (Delgado \& Stefancic, 2001). Entrance into the college-preparatory classes, including Advanced Placement (AP), bestows a certain amount of power and prestige, with students receiving tangible benefits ranging from reduced college tuition costs to a greater likelihood of earning an advanced college degree (Bleske-Rechek, Lubinski, \& Benbow, 2004). Simply put, students in higher tracked classes have a greater connection to resources as they progress - resources that people in power have motivation to protect. In American society at large, critical race theorists point out that Whiteness is a persistent hallmark of power and wealth (Delgado \& Stefancic, 2001; LadsonBillings, 1998; Ladson-Billings \& Tate, 1995; Solórzano \& Bernal, 2001; Solórzano \& Yosso, 2002). When Black and Latinx students are allowed into higher-tracked classes, that status quo is threatened.

Race, and the status it confers, is so entrenched in our society that unconscious basis often plays out unchecked. As Omi and Winant (1993) explain, racial inequality does not require overt acknowledgement to be real. The claim of colorblindness is an example of how racial discrimination is fostered despite 
possible good intentions. The act of denying that race is a factor in decisions leads to more inequity, not the end to the racially-biased system. Other examples of racially-biased actions include microaggressions, which are "subtle forms of racism in daily life, which may be hard to pinpoint as racism, but are harmful nevertheless" (Kohli \& Solórzano, 2012, p. 446). Additionally, issues such as colorism and passing for White come into play when understanding the impact of racism on students (McGee, Alvarez, \& Milner, 2016). Colorism is the difference in the way that darker-skinned students are treated than their lighter-skinned counterparts. Students who are darker may be subjected to higher levels of racial bias and racism then those who have lighter skin. Further, Students of Color who are light enough may even pass for White because other students mistake them for being of European decent based on their light skin tone, allowing them to be part of the White norms and privileges.

Therefore, it becomes crucial to break down the arguments for inherently discriminatory practices, no matter how well meaning the reasoning may be. For example, practices such as tracking are justified as a reward for hard work and effort on the part of the student (Carter, 2008; Oakes, 2005; Solórzano \& Ornelas, 2002). This notion of meritocracy ignores the inherently contextual nature of value. It assumes that all students have the same starting point and are utilizing the same 
skill set to reach the same goal (Carter, 2008; Delgado \& Stefancic, 2001).

Consequently, when the effects of systemic oppression (in this case, years of downtracking Blacks and Latinxs) are not considered while making course acceptance policies, racism is perpetuated, even if the process does not include race as a named factor. While systemic exclusionary tools such as of tracking may not be openly racist, Solórzano and Bernal (2001) would assert that tracking is just one example of educational policies and practices that operate "as a camouflage for the selfinterest, power, and privilege of dominant groups in U.S. society" (p. 313).

\section{Racialized Climate of Suburban Schools}

Suburban schools are becoming increasingly diverse as more Black and Latinx students move to the suburbs and as there are an increasing number of initiatives allowing for inter-district transfers (Orfield \& Luce, 2013). Yet, race continues to play a central role in affecting the quality of education for underrepresented minority students, even as their numbers grow within highlyresourced suburban schools (Chapman, 2013). Researchers in suburban schools have found that Black and Latinx students are underrepresented in higher-level classes and overrepresented in the Special Education and lower level classes (Allen \& Griffin, 2006; Chapman, 2013, 2014; O’Connor, et al., 2011). When a Black or Latinx student does get into higher-level classes, they are subjected to racial 
isolation and lack of support (Chapman, 2013, 2014; Diamond, Lewis, \& Gordon, 2007; Ispa-Landa \& Conwell, 2015; Nunn, 2011).

The prevalence of dysconscious racism, the acceptance of dominant White norms and privileges as the defining benchmark for success, creates school cultures with White-dominate achievement hierarchies (King, 1991). These White-dominant achievement hierarchies within suburban schools are so strong that groups seen as excelling in academics, such as Asian students, are explicitly connected with this idea of White success (O'Connor, et al., 2011; Muller, et al., 2010; Nunn, 2011). In a comparative study of three high schools, Nunn (2011) shows that the climates of the suburban schools investigated, unlike the urban school, contributed to the racialization of educational success. This study is particularly interesting because the classroom environments of the suburban high schools specifically were shown to perpetuate the segregation established by institutional structures like tracking. This environment contributed to the White and Latinx students viewing White and Asian students as the ones belonging in upper-track classes, while perceiving Latinxs as not valuing school enough (Nunn, 2011).

Before Nunn's study, Diamond et al. (2007) had previously examined how school structures shape a school culture with a racialized definition of student success. Focusing on just one suburban high school, 70 Black and White students 
were interviewed. The researchers noted that racial isolation, lack of support, and low level of self-efficacy often led Black students to self-select out of the more challenging courses. Additionally, the predominance of White teachers and students with negative views of the ability of Black students to achieve in the higher-level courses produced an environment unconducive to learning for them (Diamond et al., 2007).

Studies like Diamond et al. (2007) and Nunn (2011) demonstrate that, while school policies and practices have changed in the years since desegregation became law, the racial biases and attitudes of educators have not necessarily evolved to reflect this change. So, when teachers, counselors, and administrators hold deficit views toward Black and Latinx students, the school climate continues to negatively impact their academic achievement (Chapman, 2013, 2014; López, 2006; Modica, 2015; Nunn, 2011). Further demonstration of this concept was established in Chapman's 2014 study of almost 100 students from six different secondary schools, across four suburban school districts. Chapman used a wider cross-section of schools than the previous studies discussed, which serves to highlight how heavily the actions of teachers and counselors influenced the academic opportunities given to Black and Latinx students. Across all of the focus groups in Chapman's study, the Black and Latinx students reported being marginalized and unsupported by the 
adults in their school, leading to the identification of rigorous curricular spaces as being the providence of White students (pp. 322).

Indeed, the racialized culture can be so entrenched that even schools that are self-described as open and accepting create educational environments that are not equitable to or supportive of Black and Latinx students. Modica (2015) uncovered buried racial biases that continued to preserve race-based hierarchical power structures in her in-depth look at a mixed-race suburban high school. White staff and students alike expressed a desire to discount race as a factor in academic success, instead blaming the Black and Latinx students for their poor academic outcomes. In fact, Modica discovered that many of the White participants would go on the defensive to ensure that they were not called racist or to find ways to become victims themselves. Race was a taboo subject, which meant that attempts to get to the root causes of inequitable educational outcomes were blocked by the refusal to admit the structural impact of race. For example, one teacher purposefully avoided considering why Black students were the only ones failing one of her tests, and so to prevent others from calling her racist, she simply raised the cut-off point for a failing grade such that the group included White students. She then created an intervention for all of them. In this way, her refusal to discuss race worked to reinforce negative racial perceptions and relationships, and these had profound 
effects on the overall academic achievement of the Black and Latinx students (Modica, 2015).

Conversely, Black students who attend predominantly Black and Latinx neighborhood schools did not report that their schools were successful (or not) based on race (Allen \& Griffin, 2006; Ispa-Landa, 2013; Ispa-Landa \& Conwell, 2015). Black students from the same neighborhood, but attending two different schools, were interviewed by Ispa-Landa and Conwell (2015). The first group participated in a program that bussed them from their urban neighborhood to an affluent, mostly White suburban school where academic success was perceived as a White domain. As a result, this group of students had to struggle to overcome damaging racial stereotypes to achieve academically. The second group of students was waitlisted for the same program, but attended their own neighborhood schools. These students listed qualities such as caring teachers, school safety, and highquality programs as the reasons for academic success, which the researchers interpreted to mean that racial stereotypes of academic success were not germane to them (Ispa-Landa \& Conwell, 2015). Viewed in conjunction with the previous studies, the findings from this study plainly accentuate the impact that a raciallydefined school culture and climate has on the students within the school. By juxtaposing the differing realities of the two groups of students, one attending a 
White school and one attending their diverse neighborhood school, Ispa-Landa and Conwell's (2015) investigation indicates that White-dominate achievement hierarchies are not inevitable. Rather, it is possible to define success by a myriad of standards that does not elevate one race or culture over another. However, for educational leaders wishing to disrupt these hierarchies in predominately White and Asian schools, the question of how to use this information to take action still remains.

As these and other studies have shown, institutionalized racism grows when damaging educational practices and norms are left unchecked and the root causes labeled untouchable. By collecting data at a school that proclaims itself open and supportive, this dissertation privileged the experiences of Black and Latinx students at the school by providing a forum for them to start an intentional conversation about race. These conversations unearthed many stories counter to the caring and equitable front maintained by the public persona of the school. Only when the actual impact of the climate and culture of the school on all students, especially historically marginalized groups, is acknowledged can adjustments be made. For educational leaders in suburban schools, this means incorporating the contrasting experiences of the underrepresented students into the prevailing school climate so that any proposed action is grounded in a more authentic multi-dimensional reality. 


\section{Student Responses to Racialized Educational Experiences}

When faced with the perceptions and experiences imbued with negative racial stereotypes, Black and Latinx students respond in a variety of ways. While some of the foundational research on this topic has focused on oppositional and often damaging responses to the White power dynamic (Fordham \& Ogbu, 1986; Matute-Bianchi, 1986; Ogbu, 1991, 2003), many recent researchers are finding that Black and Latinx students respond to racialized educational experiences in more dynamic and often positive ways (Akom, 2003; Andrews, 2009; Carter, 2007, 2008; O’Connor, et al., 2011; Rivera, 2014; Solórzano \& Bernal, 2001). In fact, Black and Latinx students have been shown to respond to these negative racial stereotypes and biased school structures by increasing their school achievement, thereby resisting the racist assumptions made about them. Referred to as "transformative resistance" (Cammarota, 2004; Solórzano \& Bernal, 2001) or "academic resilience" (Gayles, 2005), this effort by students to "prove them wrong" (Yosso, 2002) counters earlier claims that underrepresented minorities typically take on an oppositional culture to cope with racism.

To resist racialized, and often racist, school environments and structures, Andrews (2009) found that Black students who achieved in school did so by understanding how racial inequities functioned to potentially derail their success, as 
well as conceptualizing their success as a point of pride as a Black person. By conducting in-depth one-on-one interviews of nine high-achieving Black students in a predominantly White high school, as well as observing them in classrooms, group meetings, and school functions, Andrews was able to show how successful Black students came to identify themselves as achievers even when their school environment presented academic achievement as a White phenomenon. Key to their ability to defy the negative narratives about their (in)ability to achieve was a positive attitude about being Black, which the students could often articulate as having come from their families and friends. This meant they had developed a conscious understanding of the effects of racism in society and how that would impact their lives and futures in ways White students did not have to contend with. Ultimately, Andrews (2009) concluded that the path between the racialized notions of success they had to actively contend with and their own self-described identity as achievers was complex and needed to be explored further. My research seeks to extend this study by investigating the tools successful Students of Color use to grapple with the effects of racialized cultures of academic achievement within their school and how a school leader can act to advance a vision of equity. As a member of the school community, my knowledge of the school culture enabled me to craft a methodological approach aimed at enacting the equitable vision I wish to develop. 
Rather then meet one-on-one with students, as Andrews did, I used focus groups to offset my power as a school leader and legitimize their realities (Madriz, 1998).

As a further focus on the wide variety of responses students can have to the racism woven onto schools, Cammarota (2004) completed a study of 40 Latinx youth on the West Coast. This seven-year ethnography developed focused portraits of six of the original 40, with a particular focus on how gender intersected with racial factors to influence responses to education. For both Latina and Latino students, having family and community support was vital to the development of transformative resistance, which helped some achieve academic success. When this support was not evident, students struggled to overcome the structural inequities present within the school system, so they would often fail to graduate high school (Cammarota, 2004). Similar findings were reported in a study completed by Allen and Griffin (2006), which showed how crucial peer support was for college-focused Black students at the suburban high school examined. High-achieving Black students actively sought out peers to help resist the racialized environment that worked against their success. Both of these studies reflect the experiences of the students in the study by Andrews (2009), who were able to clearly express the positive influence that their friends and family had on them. 
How Students of Color react to the White-dominate achievement hierarchies created by dysconscious racism is further expounded on by Gordon's (2012) research, which produced a picture of the "lived experiences" of four Black males in a mostly White suburban school. Gordon utilized a life history approach to privilege the information gathered from participants and understand each individual's academic and social life in the context of being a Black student in a racially charged educational environment. This study uncovered further examples of how students were able to positively resist racist assumptions made about their academic abilities while maintaining pride in themselves and their ethnicity. Mirroring the research previously discussed by Cammarota (2004), Allen and Griffin (2006), and Andrews (2009), this study further noted that the students pointed to peers at school, as well as community and family support outside of school, as allies in helping them to construct a positive view of themselves as Black achievers (Gordon, 2012).

My research builds upon the findings of these studies by utilizing focus groups to validate the experiences of the Black and Latinx students in one such racially charged educational environment. The conversations that arise from interacting with other students with similar experiences can assist school leadership in formulating next steps that would truly support academic success for Black and 
Latinx students. In fact, creating a plan to eliminate institutionalized racism necessitates the participation of the entire school community, including students (Noonan \& Renihan, 2006; Quantz, Rogers, \& Dantley, 1991; Smith, 2005; Khalifa, et al., 2016). Additionally, focus group interviews have been found to shrink the space between the researcher and the participants (Madriz, 1998). For this dissertation, the use of focus groups allowed this leader-researcher the opportunity to take part in the change process from the ground up, while simultaneously validating the significance of the experiences of the students and the goal of racial equity in schooling (Ruebling, Stow, Kayona, \& Clarke, 2004;

Quantz, et al., 1991).

\section{Culturally Responsive School Leadership}

A leader dedicated to social justice action and wishing to embody democratic principles must acknowledge the centrality of race in the cause of inequitably educational outcomes before embarking upon any systemic reform. In order to close the gap in educational opportunities and increase academic success for all students, it is imperative for school leaders to institute reforms that address the racial, social, and economic disparities embedded in the school's systems (Theoharis, 2007; Theoharis \& Haddix, 2011; Cooper, 2009; Shields, 2009, 2010;

Khalifa, 2011; Khalifa, et al., 2016). Culturally Responsive School Leadership 
(CRSL) shows promise in helping leaders bridging the gap caused by ongoing dysconscious racism embedded within educational systems, policies, and practices (Khalifa, et al., 2016; Madhlangobe \& Gordon, 2012). While various forms of leadership have been described as social justice (Theoharis, 2007) or transformative (Shields, 2010), CRSL moves beyond the resistance and disruption of discriminatory educational systems and practices that these leadership styles employ. A Culturally Responsive School Leader will not only confront inequitable educational practices, they will actively work to create new systems and practices that value and affirm the intrinsic worth of marginalized students and their families (Khalifa, et al., 2016; Madhlangobe \& Gordon, 2012). To frame the steps a school leader must take in to be a Culturally Responsive School Leader, Khalifa, et al. (2016) identified four categories that encompass their actions: critical selfreflection, developing culturally responsive school teachers and curriculum, promoting culturally responsive and inclusive school environments, and engaging students and parents in community contexts.

Critical Self-reflection. In order to initiate, lead, and facilitate equity action at a school site, school leaders must start from within and actively participate in critical self-reflection. It is paramount for Culturally Responsive School Leaders to scrutinize their own assumptions, biases, and values that underpin their decisions 
before, during, and after any actions undertaken (Khalifa, et al., 2016;

Madhlangobe \& Gordon, 2012; Theoharis \& Haddix, 2011; Cooper, 2009). By consciously probing their own decision-making process from beginning to end, Culturally Responsive School Leaders ensure that the intent and impact of their actions are aligned and do not inadvertently undermine their anti-racist goals. When left unexamined, word and deed can become easily uncoupled. For example, employing a comparative case study, Cooper (2009) found a disconnection between the words and actions of two school leaders grappling with cultural and racial shifts over a two-year period. While making claims about the need to address inequities within their schools, the deficit thinking about the students and their families continued in how programs were implemented and minorities were discussed (Cooper, 2009). Cooper's study confirms that without the foundation of critical self-reflection, decisions and actions will continue to follow the dominant structures already in place. Designing an affirmative study that pushed back at the prevailing narrative about Black and Latinx students not being successful meant that I had to begin with my own biases and assumptions so that I could ensure that the recommendations would not fall into the same trap as Cooper's participants.

\section{Developing Culturally Responsive School Teacher and Curriculum.}

Whether called Culturally Responsive (Gay, 1994), Culturally Relevant (Ladson- 
Billings, 1995), or Culturally Sustaining Pedagogy (Paris, 2012), this practice has been shown to be a powerful way to establish equitable educational policies and practices, especially within the context of the classroom experience (Brown-Jeffy, \& Cooper, 2011; Dee \& Penner, 2016; Dover, 2013). The intent of Culturally Responsive/Relevant Education (CRE) is to treat people from all backgrounds and cultures with respect and to confirm the belief that students bring assets from their own culture into the classroom. With this foundational belief in place, teachers embracing CRE differentiate the curriculum and instruction to connect with the various cultures and needs within the classroom (Aronson \& Laughter, 2016; Dover, 2013; Brown-Jeffy \& Cooper, 2011; Dee \& Penner, 2016; Paris, 2012; Ladson-Billings, 1995; Ladson-Billings \& Tate, 1995). In a recent quantitative study of CRE, researchers Dee and Penner (2016) demonstrated significant increases in ninth-grade student attendance (by 21\%), course credits earned (by 23 credits), and overall GPAs (by 1.4 points) when they participated in an ethnic studies course utilizing CRE. The large positive gains in critical academic areas offers a persuasive endorsement of CRE's effectiveness in systemically addressing the educational inequities that have affected Black and Latinx students. It is often up to school principals to put these programs into place, which means that Culturally Responsive School Leaders have a powerful effect on teacher instruction 
and student achievement, especially when it comes to implementing CRE across the school (Branch, Hanushek, \& Rivkin, 2013; Khalifa, et al., 2016).

\section{Promoting Culturally Responsive and Inclusive School Environments.}

Deficit thinking, or the blaming of students for their lack of achievement, has perpetuated the idea that these students are not able to attain success at school (Garcia \& Guerra, 2004; Childress, et al., 2009; Geiser \& Santelices, 2004; Darling-Hammond, 2010; Oakes, 2005). When the structures and practices at a school allow deficit thinking, the culture of the school undermines the worth and value of marginalized students. The antithesis of this idea is maintaining high expectations for all students, which is at the core of an open and culturally responsive school culture (Smith, 2005; Theoharis, 2007; Shields, 2009, 2010; Theoharis \& Haddix, 2011; Khalifa, et al., 2016). Through the detailed examination of two principals who led effective reforms at their respective schools, Shields (2010) demonstrated that an educational leader with the driving belief that all students can learn is imperative for an inclusive culture to flourish. This case study began with the success of the principals and then connected their outcomes to their stated beliefs and insistence of high expectations for all students. Another study completed by Mayfield and Garrison-Wade (2015) looked at one middle school's accomplishment in closing the gap in educational opportunities and increasing 
educational success for Black students. The researchers determined that professional learning was the lynchpin in turning discussions about equity into practice across the whole school, further demonstrating the importance of an entire school community engaging in dialogues around race, culture, and cultural competence. Although the research in both studies was limited in scope, it serves to establish an opening for further examinations of the practical ways in which Culturally Responsive School Leaders can create school cultures that truly support all students.

\section{Engaging Students and Parents in Community Contexts. While}

transformative and social justice leaders share much behavior with leaders from the other three categories (Smith, 2005; Theoharis, 2007; Shields 2009, 2010), an element that sets Culturally Responsive School Leaders apart is their engagement with students, parents, and community members in a way that is true to their culture and identity (Khalifa, et al., 2016). Rather than expecting families and communities to conform to the majoritarian narrative about what interacting with the school looks like, a Culturally Responsive School Leader creates opportunities to demonstrate that their community is a valued part of the school. In an effort to better understand the barriers to culturally responsive educational practices that support non-dominant cultural groups, researchers Hynds, Averill, Penetito, Meter, 
Hindle, and Faircloth (2016) examined 84 secondary schools in New Zealand. Using a mix-methods approach, the team looked at a wide variety of information, including national assessment data, school actions plans, student data, in-person interviews with staff and students, and classroom observations. What the researchers discovered is that a lack of substantive partnerships with the minority students, their families, and community was the primary cause of the barriers. This study sends a powerful message that connecting to students and their families is vital if a Culturally Responsive School Leader is to really enact the culturally responsive educational practices and school culture needed to support all students, especially the historically marginalized, in achieving academic success. 


\section{Chapter Three: Methodology}

To address the research question about the experiences of successful Black and Latinx students at a high-achieving suburban high school that is predominately White and Asian, a qualitative study of student educational experiences was designed. Data were collected from multiple focus group interview sessions with Black and Latinx students who fit the operational definition of success.

\section{Critical Race Methodology}

As a White female school leader, and therefore a member of multiple privileged groups, I am committed to making a conscious effort to acknowledge and make space for the experiences of underrepresented students. Consequently, I extended the Critical Race lens into the methodology of this study by utilizing critical race methodology (Solórzano \& Yosso, 2002) to purposefully centralize and legitimize the responses of underrepresented students who are routinely and systemically marginalized within schools. The discussions that shape policy and practice at school sites are often dominated by the marjoritarian stories (Solórzano \& Yosso, 2002) told by those who hold the power and privilege, yet the decisions made affect all students. Giving space to stories of successful Black and Latinx students to counter these marjoritarian stories is a necessary first step in reshaping the dominant deficit mindset within the system (Harper, 2015; Ladson-Billings, 
1998; Santamaría, 2014; Solórzano \& Yosso, 2002). Further, engaging marginalized students in conversations about their lived experiences in an effort to inform school-wide practices is a vital component of being a transformative and Culturally Responsive School Leader (Shields, 2004; Khalifa, et al., 2016).

\section{Role of the Researcher}

Through my leadership position at Creekside High School (CSHS), I knew many of the students I recruited to be in the focus groups. Most of my interactions with them had been of a positive nature, such as attending their events, providing them with support and assistance, or interacting with them during breaks and lunch. Despite my obvious position of power and authority, I had worked hard prior to this research to develop meaningful relationships with all students, so they were willing to volunteer for this study. With minority students in particular, I have purposefully cultivated an honest and open relationship, especially in terms of my willingness to engage with them in dialogues about racism and bias.

My years of experience as a student and educator in culturally-diverse schools has simultaneously been my challenge and my strength. From a young age, I have often been surrounded by people who did not reflect my own European background. This continued into my school-age years and beyond. I was taught by my parents to not see a difference between me and them, but I saw fairly early on 
that others did not treat everyone the same. This struck me as unfair and I approached it in what I thought was a straight-forward way. Treat everyone equally - exactly the same - and there would be no problems. I did not see race or ethnicity, rather I believed that everyone was simply part of the human race. Colorblindness was the bedrock of my belief system well into my career as an educator. Not until I began working with a White colleague who introduced me to culturally responsive pedagogical strategies did I begin to unpack my assumptions about what my colorblindness actually meant (Ladson-Billings, 1995; Matias, 2013). Even then, I had a long journey in front of me as I began to confront my White privilege, but my desire to support my students pushed me to continue reflecting on my own biases. Through my training to be a school administrator, and now in my doctoral studies, I have driven myself to erode the assumptions that I made in the past and replace them with a multifaceted understanding of the reality my students actually live in (Theoharis \& Haddix, 2011; Matias, Viesca, GarrisonWade, Tandon, \& Galindo, 2014). This study was conceived of as a continuation of this desire to improve the opportunity for all students to succeed.

\section{Context}

The data were collected at a high-achieving, affluent suburban high school located in Northern California. One of two comprehensive high schools 
in a small, unified school district, Creekside High School (name changed for confidentiality) has 1936 students, most of whom are socioeconomically affluent. Free and reduced lunch participation has remained at approximately 7\% since 2009 . The majority of students are White (41\%) or Asian (48\%), with only $2 \%$ identifying as Black and 9\% identifying as Latinx. Additionally, the teachers, administrators, and counselors are overwhelmingly White (77\%), followed by Asian (11\%), Latinx (9\%), and Black (3\%). Historically, student academic achievement, graduation rates, and college acceptance rates have been significantly lower for underrepresented minorities across the entire district. In 2013 for example, 21 Black students graduated from the district, but only 7 of those students (or $33 \%$ ) were qualified to apply to either the California State University (CSU) or University of California (UC) colleges. Latinx students faired only somewhat better, with $55 \%$ being qualified for either CSU or UC admissions.

\section{Participant Selection}

Students were chosen to participant based on state- and federal-collected identification as Black or Latinx students enrolled at Creekside High School in

grades 10 through 12 . Students in $9^{\text {th }}$ grade were not selected given their limited high school experiences. Since preparing students to be ready for college is a stated goal for public high schools (Espenshade, \& Radford, 2009; Nunn, 2011), and 
colleges have more specific requirements than what is necessary for a high school diploma, only students who had successfully completed all of the collegepreparatory courses were included. To be eligible to apply to the California State University (CSU) system, a student must have at least a $2.0 \mathrm{GPA}$ in all the collegeprep courses listed in the various categories, called the A-G subject requirements. Students meet the A-G requirements by completing cores subjects, such as Mathematics, English, and Science, and demonstrating some breadth by selecting from various electives, including Visual and Performing Arts or Career Technical Education. Naturally, the higher the GPA, the more competitive a student is in college admissions (CSUMentor, n.d.). However, given the small pool of Black and Latinx students, I included GPAs as low as 2.0 in the A-G courses, with a majority being higher than 2.5 , to serve as the definition of "successful" for this study.

Of the students who met the selection criteria, 16 agreed to participate in the study, with half being female and half male. Seven of the students were Black and nine were Latinx. At the time of the focus groups, four students were $10^{\text {th }}$ graders, seven were $11^{\text {th }}$ graders, and five were $12^{\text {th }}$ graders. Students were organized into groups based on ethnicity, with a minimum of 2 students in each group. The groups met two separate times in the spring semester of one school year, for a minimum of 
30 minutes each session. However, not all of the students participated in the second session. See Table 1 below for the list of participants and their demographics.

\begin{tabular}{|c|c|c|c|c|c|}
\hline Name & $\begin{array}{c}\text { Grade } \\
\text { Level } \\
\end{array}$ & Race & Gender & $\begin{array}{l}\text { A-G } \\
\text { GPA }\end{array}$ & Session \\
\hline \multicolumn{6}{|l|}{ Group \#1 } \\
\hline Alisha & 11 & Black & $\mathrm{F}$ & 2.96 & $1+2$ \\
\hline Brianna & 11 & Black & $\mathrm{F}$ & 3.54 & $1+2$ \\
\hline Lionel & 12 & Black & $\mathrm{M}$ & 2.22 & $1+2$ \\
\hline Trent & 12 & Black & $\mathrm{M}$ & 4.43 & 1 \\
\hline \multicolumn{6}{|l|}{ Group \#2 } \\
\hline Regina & 11 & Latinx & $\mathrm{F}$ & 3.19 & $1+2$ \\
\hline Francisca & 11 & Latinx & $\mathrm{F}$ & 3.58 & $1+2$ \\
\hline \multicolumn{6}{|l|}{ Group \#3 } \\
\hline Samantha & 10 & Latinx & $\mathrm{F}$ & 3.28 & $1+2$ \\
\hline Maria & 10 & Latinx & $\mathrm{F}$ & 4.00 & $1+2$ \\
\hline Jesus & 11 & Latinx & $\mathrm{M}$ & 2.26 & $1+2$ \\
\hline Gabriel & 11 & Latinx & $\mathrm{M}$ & 2.82 & $1+2$ \\
\hline \multicolumn{6}{|l|}{ Group \#4 } \\
\hline Anthony & 10 & Black & $\mathrm{M}$ & 2.06 & $1+2$ \\
\hline Caleb & 10 & Black & $M$ & 2.29 & $1+2$ \\
\hline Tiana & 12 & Black & $\mathrm{F}$ & 3.06 & 1 \\
\hline \multicolumn{6}{|l|}{ Group \#5 } \\
\hline Fernando & 11 & Latinx & $\mathrm{M}$ & 3.83 & $1+2$ \\
\hline Luis & 12 & Latinx & $\mathrm{M}$ & 2.89 & $1+2$ \\
\hline Silvia & 12 & Latinx & $\mathrm{F}$ & 3.36 & $1+2$ \\
\hline
\end{tabular}

While the number of Black students on Creekside High School's campus is not equal to that of the Latinx students ( $2 \%$ compared to $10 \%$ ), the experiences of Black students are distinctive "due to the legacy and implications of slavery and the insinuation of inferiority that justified treating Black people as less than human" 
(Boylorn, 2010, p. 6). Thus, my intention in including a similar number of Black students as Latinx students was to account for the historical subjugation of this group.

\section{Ethics and Protection of Human Subjects}

To ensure that all ethical principles were observed during this study, a full IRB protocol was submitted and approved through the university and school district. Within the protocol, my intent to support students and avoid harming them is established through submission of parental permission letters, together with the consent and assent forms for the students. All inclusion criteria, recruitment procedures, and research methods were described to the students and their parents, including the assurance that their identity would be kept confidential. I also described how the identity of the school district, school, and the student participants in the collection of the data and report of the findings would be obscured.

\section{Data Collection}

Data collection began by cross-referencing student racial profiles in the school database with their GPAs. "Academically successful" Black and Latinx students were defined as having at least a GPA of 2.0 or higher in all required CSU and UC A-G courses. Using this list of potential study participants, I recruited the students to take part in the study by meeting with them in groups in a library study 
room. During this recruitment meeting, I explained my intentions as a researcher, the research question, and its purpose. The interested students provided me with their email address and then returned their signed consent or assent forms and their parent's permission letters (if applicable) to me on a separate day. I used their email addresses to communicate with them about the scheduling of the interviews and remind them about returning necessary paperwork.

The 16 students who volunteered were invited to two focus group interviews, which took place over the course of the spring semester. Of the 16 students, there were two who only attended the first session and are noted in Table 1. During the focus group interviews, students were encouraged to respond to my questions and interact with each other about the topics discussed. The conversations began with a discussion about success in general, followed by academic success at Creekside High School specifically, and then culminating in the impact of race on their academic success at school. Appendix $A$ has the protocol used during the interviews, although I did deviate from the question bank if a topic that the students brought up merited further exploration. The conversations were facilitated by a short writing exercise at the beginning and end of each focus group session. The intention of the journal writings was to allow the students time to gather their thoughts or process what had been said. The writing exercise also bridged the gap 
from the previous session and guided the second round of interviews. Students were explicitly told that I would be reading the journal entries, but not sharing them with the other students. An audio recording was taken during each interview and professionally transcribed afterwards.

To address the clear power imbalance between me, as a White Assistant Principal, and the students, I made sure that there were at least two students in each focus group session. Additionally, all of the sessions were held outside of the Main office. Six sessions were held in a library study room, and four sessions were held in a conference room in a department office. All of the rooms used were in areas easily accessible to and frequented by students, while not being specifically associated with my role as an Assistant Principal.

\section{Data Analysis}

With the centralization of the student narratives in mind, data analysis began from a grounded theory perspective, using several rounds of coding across the data to theorize conceptual relationships within the data. Specifically, I began with the exact words of the students through in-vivo coding to preserve the voice of the student participants (Charmaz, 2006; Saldaña, 2013; Miles, Huberman, \& Saldaña, 2014). Charmaz (2005) contends that using grounded theory in this type of social justice research ties the findings to the environment being studied and allows these 
findings to move past a simple summary of the events. Memos and jottings, written from the beginning of data collection and continuing through the coding process, allowed me to interrogate these codes and then group them into descriptive categories and emerging themes (Miles, Huberman, \& Saldaña, 2014; Saldaña, 2013). I worked with NVIVO, a data analysis software, so that the codes, categories, and themes could be saved, organized, and manipulated as new insights emerged.

As the codes evolved into categories in the second cycle of coding, I began to focus on the actions that the students were engaging in within the categories. In this manner, the connection between grounded theory and figured worlds emerged. Both emphasize the importance of interaction and enacted processes in order to fully grasp the world being investigated (Holland et al., 1998; Charmaz, 2005, 2006). It is through their interactions with their fellow students and other members of their figured world of academic achievement that the successful Black and Latinx students are able to determine their own place within that world. Calling attention to these interactions is vital to understanding the current reality that the students navigate, so process coding, also known as action coding, functioned to highlight their responses to the various factors within their world (Saldaña, 2013). For example, one of the prominent categories was grades, which lead to me to 
wonder what the students were doing with the grades. How were they interacting with others about the grades? As the interactions of the students with the people and concepts of the figured world took shape, I was then able to apply the conceptual frame through the use of Hatt's (2007) three elements, Cultural Artifacts, Discourse, and Identity. These elements became the final themes that evolved from the data, making a direct link to the conceptual frame and taking the findings further than the topical categories from the second cycle. 


\section{Chapter Four: Findings}

This study examined the educational experiences of academically successful Black and Latinx students at a largely White and Asian high-achieving suburban high school. With the focus on Students of Color who are successful, this research affirmed the resourcefulness of historically underrepresented students with the intention of replicating the factors they indicated as providing them with support. In the interest of creating a truly equitable system of education for all students, this study aimed to find ways to include the voices of disenfranchised students in the decision-making process. Exploring the lived experiences of students lays the foundation for school leaders to make empathic decisions regarding the implementation of policies and practices that ultimately impact the quality of student learning.

This dissertation used focus group interviews to answer the following question: What are the experiences of successful Black and Latinx students at a high-achieving, predominantly White and Asian suburban high school? 16 students identified as successful participated in up to two rounds of focus group interviews. "Successful" was defined as having completed all course requirements with high enough grades to qualify for entrance into the California State University system. Each group was organized around a single ethnicity, either Black or Latinx, with a 
mix of grades and genders. The students were asked about their views on success, strategies for how they achieved it, and challenges they have overcome, especially in the context of Creekside High School (CSHS). Additionally, the students shared how their race and the racism they faced in their school careers, particularly at CSHS, impacted them.

\section{Figured Worlds Framework}

The findings are presented using the framework of the figured world of academic achievement at CSHS, which encompasses what it means to be a successful student at this school. More specifically, it defines who is considered successful, and what opportunities and supports student are given so that they may take on or continue to inhabit the role of successful student. I will discuss my findings utilizing the structure that Hatt (2007) distilled from the work of Holland et al. (1998), which established three fundamental elements of the figure world: cultural artifacts, discourse, and identity. First, I will spotlight the cultural artifacts, material and conceptual, that the students affiliate with being successful at CSHS. Next, I will examine the ways in which the students used their stories to explicate the discourse of success they navigated daily. The third element of the framework will look at how the students see themselves within the figured world of academic achievement and then form their own identities as successful students through 
authoring their own world. Finally, I will present the solutions and ideas that the students felt would address the challenges they faced within the racialized world of academic success at CSHS.

Cultural Artifacts. Cultural artifacts are described by Holland et al. (1998) as physical manifestations or theoretical tools "by which figured worlds are evoked, collectively developed, individually learned, and made socially and personally powerful" (p. 61). When engaging with others in their figured worlds, the artifacts become an axis around which the interactions revolve, thus instilled with symbolic meaning that becomes collectively understood. The meaning of the artifacts develops through discussions, activities, and involvement with other people, in turn shaping responses and perceptions of self and others. The students in this study described multiple artifacts, both tangible objects and well-defined ideas, that they used to position themselves within their figured world of academic success at CSHS.

Acceptance into the right college. As a concept, being accepted into a college with the right credentials is the definitive cultural artifact at CSHS. This abstract idea took shape as an artifact that students had to contend with beginning in the first round of the focus groups, when I asked the students what success meant to them. Across all the focus groups, college was given as the ultimate expectation to 
reach. For example, Anthony (Black, $10^{\text {th }}$ grade) said, "To live up to the standard of your family and go above and beyond. Like on my mom's side, I'll be fourth generation in college. And I'm in a family of educators, so go big or go home, I guess." Along the same lines, Samantha (Latinx, $10^{\text {th }}$ grade) said:

Because my sister applied for like 15 colleges and she got scholarships for like 14 of them so they have this really high...like oh, if she can do it you have to be able to do it. . . whenever you go and see your family they're like, "How is school going? Have you picked your college?" . . because people before you have succeeded a ton, you're supposed to be able to do the exact same.

Alisha (Black, $11^{\text {th }}$ grade) pointed out, "I've been at CSHS honestly for three years now and it's definitely been stressed that right after high school you go to college." While their definition of success did include being proud of themselves for reaching goals, most of their examples focused on how being accepted into college was the benchmark for being successful. The students were describing the dominant narrative at this affluent, high-achieving high school, where being accepted into a top-tier public and private universities is expected and has become the ultimate conceptual artifact associated with success at CSHS. 
This abstract artifact of acceptance into the "right" college has taken on such strength at the school that there are even mainstream attempts to counteract it. For example, in the three years I have served as Assistant Principal, beginning in the early spring students who have received rejection letters from colleges spontaneously post them on the wall outside of the student activities office. The posted letters are unredacted, with their names intact. This student-led action seems at first blush to be saying that it is okay not to get into a college that was applied to. But if examined further, it is also sending a message that is, in truth, aligned with the dominate narrative. This deeper message is more of a "humble brag," essentially saying that they were good enough to apply to Harvard/Stanford/MIT, even if they did not get in. Students are now using this wall of rejection as a reason to apply to as many as ten or more colleges in their Senior year.

Grades. All other artifacts are therefore defined in relation to striving for and being accepted into exclusive postsecondary schools. This is especially the case in regards to grades received for assignments, tests, and courses. All of the students readily described the role that grades played in indicating to themselves and others that they were successful. Joaquin (Latinx, $11^{\text {th }}$ grade) summed it up when he said:

I think still at CSHS, just the environment of other people around you where being successful means having a 4.0 throughout the whole thing and getting 
really good $\mathrm{ACT}$ and SAT test scores and all that. It's a lot of pressure and definitely if you're falling behind in the class where you have a bunch of people who are super smart and then you get back a test and it's like a $\mathrm{C}$ and everyone else has an A, then you're kind of that one person that doesn't understand it too well and it just kind of makes you feel bad because everyone else around you is super smart.

Several students across the focus groups shared times that grades were used to indicate their position within the figured world of success. A discussion with Regina (Latinx, $11^{\text {th }}$ grade) and Francisca (Latinx, $11^{\text {th }}$ grade) epitomized this phenomenon:

Interviewer: So, when you say [the teasing is] about grades, it's like people making fun of the grades that you earned or the grade that you didn't earn?

Regina: Yeah, umm-hmm. "Maybe next time you should try harder." It's like, I was already trying the hardest that I possibly could!

Interviewer: So, there's an assumption that you were just being lazy?

Regina: Umm-hmm. 
Francisca: I agree with the whole grade thing because I do know a lot of people here like to compare their grades and when they get a test back they're always asking each other, "Oh, what did you get? What did you get?" And I know some people, like I know it happened to me once, where I didn't get a good grade and a friend of mine did and when I told her the grade that I got she was like, "Oh." Like as if she was like, I felt like that "Oh" was like (trailing off)

Regina: Condescending?

Francisca: Yeah and kind of rude-ish, too. Like saying, it felt like as if she was judging me, I guess, because of the grade.

Being considered lazy or judged because of a low grade means that, at least at that time, Francisca and Regina do not have the "proof" that they are successful. Their grade has now removed their status as successful, at least momentarily. Regina detailed another experience that also distinctly illustrated this:

But so someone asked me what my grade was on the test and I didn't want to tell her, so I just, so she asked me "Is it lower than an A?" And I just agreed and then she asked me if it was a B and I had gotten a B, I had gotten a B minus, so I said "Yes." And she looked at me and then she told me 
"Wow, you should probably get that up if you want to go to college." - and I was just like great, that's really not helpful at all because it was one of the best tests that I had done in that class.

Regina's reaction to what her classmate told her indicates the power of the grade as an artifact. Her place within the figured world was questioned because her grade was deemed too low to compete for a spot in a college that only accepts A's on assignments.

Racialization of grades. For these Students of Color, grades have definite racial meanings as well. Lionel (Black, $12^{\text {th }}$ grade) recounts how he has experienced racism through microaggressions regarding his grades:

Going to college is even bigger [accomplishment for Black students] because expectations are always low as an African American ... I get that vibe throughout campus. It's like when you get an A on a test and like [other students say] "You got an A on the test?" You see the body language. People, you know, look at the test. [picks up a paper] You see 'em, you know, out of the corner of your eye, look at your test. . So I'm like, "Yeah, Ummhum [holding the paper up like it's his test]. See this?" [with a defiant look on his face]. 
Alisha vigorously agreed with Lionel as he was narrating this incident, which served to validate him and increase his willingness to give details. Lionel's experience with people doubting his ability because he is Black put him in the unfair position of having to justify his grades while he navigates the figured world of success. As he points out, White and Asian students do not have to contend with this additional challenge.

In the same vein, the four students in the second round of one of the Latinx focus groups began trading their own experiences with the racial meanings associated with grades at CSHS. Joaquin, Samantha, Gabriel ( $11^{\text {th }}$ grade) and Maria ( $10^{\text {th }}$ grade) all began discussing how other students on campus respond to their good grades:

Joaquin: If I'm talking about my grades and my grades are decent, and sometimes they're really good, and I just say that to some people that don't really know me, or that have just met me, sometimes they get surprised.

Maria: $\quad$ Like "Wow, you got an A?"

Joaquin: $\quad$ Where it's like, "Hold up. Do you think that because of my race I'm not thinking exactly about my future, what I want in the future?"... 
Gabriel: $\quad$ Yeah.

Maria: $\quad$.. You either don't care about what other people think and you strive every day to break that stereotype, or you just let it be you because that's all anyone is ever going to think.

Gabriel: Last year one of the things that pissed me off was that I was in physics last year as a sophomore and I was doing the math and everything. It was kind of hard. . And one of the students comes up to me in one of our lab groups and he sees me doing all this and I'm getting it all right. "Oh, you're one of the smart ones" and I didn't acknowledge it at first, but he meant, "Oh, you're one of the smart Mexicans," assuming like, they're all incompetent, non-caring-about-school Mexicans. So, I was like "What?!" I didn’t acknowledge it because I was in class, I didn't want to get into a fight. I'm really short-tempered, so if you piss me off I might start swinging. So I try to stay really calm and I don't acknowledge it. Another thing is that, this happened this year during math and they passed back our midterm scores and one of the Asian students in our class says, "Oh, let me see 
your scores, let me see your scores," like trying to mock me, because he got really ... OK, he thinks he's the best student in the class because of his race and when I showed him my scores he was surprised that I had better scores than him. So, it was kind of just like "What?"

Maria: Like "Why are you surprised?"

Samantha: $\quad$ You kind of want to ask that question, like "What? What do you mean I'm one of the smart ones?" And look them in the eye.

Gabriel: $\quad$ Yeah, when they question your intelligence because of your race that pisses me off.

Gabriel's experience with surprise in his good grades in math and science were echoed by the other students in his focus group. For them, it was a common occurrence for their success in these courses to be questioned, and even dismissed, due to the racial hierarchy set up within the world of success about what race was figured to earn high grades. Taken altogether, these stories illuminate how the students must contend with the power of the artifact of grades as a student and, more specifically, a student of Color. 
Discourse. When interacting with the cultural artifacts of the figured world of success at CSHS, students develop an understanding of the artifact's meaning and their own relationship to it through the discourse they engage in about it with others within that world. Discourse refers to the way an artifact acquires meaning through discussions about the object and its use by members of the figured world. The collectively understood value and power of the artifact is then associated with the individuals and activities linked to it (Holland et al., 1998).

Narrow definition of success. During the focus group sessions, the students identified a school discourse that created a very narrow definition of success. In the academic world of success at CSHS, only As on assignments are good enough and only perfect scores on standardized tests are celebrated. The pressure to succeed is often so great that even objectively good scores are decried if they do not meet the high bar. Joaquin related a story of a girl in his class who became visibly upset because she received a 32 out of a possible 36 on the ACT (a college-entrance exam) the first time she took it. To her, it was a major failure and other students in the class commiserated with her about it. The message here is that less than perfect is not good enough and will not get you into the right college. Therefore, as you are held up to the requirements of the artifact of college acceptance, you are not a successful student; you are, in fact, a failure. Through this limiting discourse, the 
students become bound by the restrictive identities provided by the figured world of success, only being able to make minor adjustments.

This confining tone and expectation about grades or scores on assessments has permeated the overall atmosphere of the school, creating a discourse that leads to a high-pressured world of academic success. Lionel described the school as competitive, but Fernando (Latinx, $11^{\text {th }}$ grade) went further, providing a stronger portrayal when he said:

We all know that the academic pressure at CSHS is tremendous ... I feel there are so many things that are expected of us. . . we're expected to do something amazing in high school to get into college.

In the same focus group, Christopher (Latinx, $12^{\text {th }}$ grade) explains that there is "a big overwhelming sense of feeling that, "Okay, I have to be on top of every single one of these things like as soon as possible or I'm going to get lost like that [he snaps]."

Hiding failure. Needing "to stay on top of" everything has created an environment at CSHS where students keep any kind of failure hidden from their peers. Ways in which the students worked to hide failure emerged through the stories the students told. While grades were shown earlier to be an important cultural artifact used like currency within the figured world, the students also talked 
about trying to avoid discussing grades. This was especially true if the grades did not measure up to the extremely high standards for CSHS students. For example, in the middle of discussing one experience, Regina explains, "I know it's not very good to share what your grades are." Since the artifact of grades helps to determine a student's standing in the figured world of academic success, it makes sense that students would want to avoid anyone knowing that they had slipped up. Maria points out that no one wants a classmate to think "Oh, wow, like they didn't get that? What?! It was so easy!'”

In an effort to hide the low grades, students are then not willing to approach teachers for help. Alisha and Lionel both shared how being afraid to appear weak stopped them from asking for help. Maria indicated that "They [students] don't want to go up to teachers and be like 'Hey, can I do test corrections?' because it's like 'Ohhhh, you went to the teacher after class." Samantha backed this up, explaining that when there is time during class to ask the teacher questions, a student needing help has to wait in line with all the other students, many of whom are asking for extra credit even when they have a relatively high grade. Thus, asking for additional support for a truly low grade becomes a publicly embarrassing experience that no one wants to have. As Samantha further explains: 
But like, that kid is still standing there and he's like "I'm going to get into Stanford and I'm only a freshman" kind of a kid. But then you're standing there like, "Hey, I failed this test, can I do test corrections?" It's really hard to go up and do that.

Recalling Joaquin's story about the girl and her "low" ACT score, the discourse around who can ask for help or share their mistakes within this figured world of academic achievement takes shape. Joaquin asserted that the only students who talked about their grades were those who had "failed" by getting what they knew everyone else would consider a high score. So, the ACT student's false public confession of failure and the freshman asking for extra credit then serve to shame into silence those who truly need help, because they fear losing status in the competitive academic world at CSHS.

In the $10^{\text {th }}$ and $11^{\text {th }}$ grade Latinx focus group, the four students also reflected on what it was like to be on the other side of that situation. As successful students, they have experienced what it's like to be the student with the good grades overhearing another student ask for help with a low grade. They discussed the etiquette of accidently eavesdropping on those types of conversations and agreed that it is important to have, as they put it, a "deadpan expression" that does not show pity, but also does not show condescension. Ultimately, they concur that there 
is no good look to give when stuck in that awkward position, but being careful to not show contempt is something they value.

Racial biases in the discourse. Adding to the predominate discourse of academic success are racial biases that make it even harder for Students of Color to claim their identities as academically successful students. Across the focus groups, the students described the successful student at CSHS as being White or Asian. Anthony, Tiana (Black, $12^{\text {th }}$ grade), and Caleb (Black, $10^{\text {th }}$ grade) referred to Black and Latinx students as "Students of Color," but put White and Asian students together as one group, having much more privilege. Regina labeled White and Asian students the "regular students" who did not require additional support to be successful. In the conversation about grades, Gabriel felt that the Asian student believed himself to be a successful student by virtue of his ethnicity. Joaquin encapsulated it by saying, "Most of the time, ... you're going to see the Asian or the White kid in the class as the kid that's doing the best in your class." Brianna (Black, $11^{\text {th }}$ grade) noted that her teachers and coaches have described her as a troublemaker, and thus are surprised at her academic ability because she is quiet. She remarks that others perceive her quiet nature as cold or detached and that her teachers think that she is either "up to no good" or is not 
interested in the curriculum. She recounted an experience with a teacher that exemplified this issue for her:

I remember one time I got like a really good grade and my teacher, she's like "Wow! Good job, I'm proud of you." And I'm just like "What?" ‘Cause to me that's like nothing, because that's what I do, or whatever.

Thus, Brianna felt the teacher's surprise at her success was condescension at the very least. Given her general success, Brianna felt that the teacher should have recognized her aptitude. Instead, the expression of surprise at Brianna's achievement highlighted what she believes was the teacher's underlying racial bias, since the teacher was treating her success as unusual or remarkable.

In the group, Brianna's story acted as a watershed moment, encouraging the others to share how being Black means that they are perceived as being angry or mean or not good students. Lionel said, "I feel like, they think I'm a bad kid, you know, and I'm not, you know. I'm just a quiet kid trying to learn." Alisha followed his comments by saying:

We for sure all got that face when you don't smile, you come off as you're pissed, you have an attitude, something's wrong, you're about to go beat somebody. Something. But the minute you come up and talk to me, I'll put on a smile, like it's a genuine smile, I'll talk to you, I'll laugh with you, it's 
no problem. I feel like it's just based on just appearance and the way you look and the minute, like she said, your demeanor, everything about your demeanor, because you know, first impression.

Lionel underscored this ordinary, everyday racism with his observation that a White male would not be noticed for having a straight face in the same way that the Black male was. He felt that a teacher will notice the Black male's face more quickly in a negative way. Alisha pointed out that they are not able to respond authentically to the racist comments because they would get in trouble if they did. Brianna and Lionel both agreed with her, collectively believing that they would be punished more severely than a White student would. At the very least, they would be judged more harshly for getting angry because they are Black.

Likewise, Silvia (Latinx, $12^{\text {th }}$ grade) shared a time where she encountered bias from other students based on race:

Silvia: I remember we [the tennis team] were driving out of school one time to go to a tennis game and there was a police car parked outside the main office. I'm like "Oh, I wonder what happened" and they [her White and Asian teammates] were like "Oh yeah, so some Mexican kid got pulled out of my class." And I was like "Why is he automatically Mexican?" 
And they were like "I don't know." And I was like "Why is he automatically Mexican? Like, I don't understand why you automatically label him as Mexican? Just because he's dark and just because he might look Latino or Hispanic, he's automatically a Mexican?" I had to stand up for myself at that point because I just felt so uncomfortable with everybody around me and I was just like, "No, like you don't know where he comes from. He could be born here, he could be born here for the past three generations and he considers himself White. Like, you don't know his life story, so why do you automatically label him as Mexican and then you make a bad name for me. Like, if I walk into a room and be like, "Oh, yes I'm Mexican," and I identify with this culture and then somebody else labels me as something negative because you've decided to label everybody who does something negative and is dark as Mexican, like I just don't feel like that does us justice at all."

Interviewer: And the very fact that they assumed that the person who got pulled out was the one was in the office. 
Silvia: $\quad$ Yeah, exactly. And it's like he could have been pulled out just to change his schedule, like you don't know. So, I just find it strange that even here, even now, that people just automatically assume terrible things of minorities and I've seen that across my four years here at CSHS where I'm constantly surprised by "Wow, I can't believe you just said that."

Experiences such as these only serve to reinforce the deficit narrative describing Students of Color at CSHS. When discussing stereotypes, Francisca and Regina brought up how expectations are low for Latinas, because they are thought to more likely be a "teen mom" than a scholar. The girls felt they had to fight this label at CSHS, which was part of a larger pattern that there was no expectation from the others within the figured world that they would be academically successful. Brianna also noted that people set a lower bar for her in terms of success due to her race. She described feeling that teachers, administrators, and her classmates seem to expect her to go only to community college, without ever transferring to a university, and think that she'll remain working in a minimumwage job. Tiana and Anthony agreed with this sentiment, both stating that Black students at CSHS are not put into higher level classes because there is a belief from 
the teachers and administration that they will not be going on to a prestigious college, so do not need these demanding classes.

Even when a student of Color does obtain the pinnacle artifact and get accepted into a top-tier college, the collective narrative searches for reasons other than ability and effort to explain how they did it. Trent (Black, $12^{\text {th }}$ grade) recounts the reaction he received from others after he had been accepted into Stanford:

If you're a minority and you get into a good school, like either everyone blames it on like affirmative action or like just 'cause the fact that you're a minority, that's like why you got into anywhere you got into... my mom was tutoring one of my friends and she told her where I got into school and like she was like "Oh, he got in because he's Black." And I'm like, "No, I didn't get in because I'm Black, I got in because I had good grades and stuff like that."

Joaquin shared a similar story about encountering bias as he was registering for courses.

Joaquin: Even for my courses for next year, the APs that I have are all core subjects. I have two APs and an honors, because I was trying to figure out one more class I had to take because I have all my credits. So, I was talking to people and they were 
looking at it and they were like "Oh, you're taking this AP?" And I'm like "Yeah," but it's this really funny feeling because I look at that and be like, "Wow, they're taking it like 'This person, who's a Latino person, is taking the exact same courses that I am.' and I'm just like "Wow."

Interviewer: Because you were talking to other races?

Joaquin: I was talking to White people and Asian people and some of my friends too. I talked to some teachers too and since I didn't have classes with them, I was in Flex time [a tutorial period] with a science teacher I didn't know, and I was like "What would you recommend for another history course?" And they were like "Let me see your schedule."

Interviewer: And they were surprised?

Joaquin: Yeah.

Interviewer: And you felt it was because of your race?

Joaquin: Yeah.

Much like Trent, Joaquin sensed a level of surprise from his classmates and teachers because, as a student of Color, he did not match the discourse about who 
successful students are, despite having the prerequisites to take the advanced level classes.

Passing for White and Colorism. The concepts of passing for White and Colorism further defining the student's experience with the racially biased discourse in the figured world of academic success at CSHS. Silvia identified herself as Mexican and Nicaraguan, but is assumed to be White based on her appearance. She shared, 'Once they [teachers] find out that I'm from Latin America, they just treat me completely differently." and will offer her academic supports for no reason other than being Latinx. Maria, who also appears to be White, talked about how her older sister, who was easily identifiable as Latinx, has been treated differently compared to herself:

I do not look Mexican at all, but my sister does. So, when we used to go out around, like with my family, they usually assume that I was the adopted one ... So, my sister has . . been put in the lower lane simply because of how she looks and that was a problem when she got here at CSHS. Like she didn't take one of the English classes as a freshman because they put her in, without her permission, they put her in the lower English lane and she's like "No, I deserve to be in the advanced English lane." So, she completely just didn't do a semester of English. It's amazing. She was put into the lower 
science lane by her 8th grade teacher and she has had a lot of the struggles . .. where it's like people assume that she's dumb and people are like "Wow, you got this, that's weird, you're Mexican. Oh my god, you're one of the smart ones." But then like me, I am as white as you can get, I am, but it's like I'm in all the advanced classes and I'm doing really well and I'm usually the only person of my race in my class. So, then when people hear that I'm Mexican and that I'm Salvadorian and native, they're like, "Wait, what?" They give a second look because I don't sound Mexican, I don't look it and I'm just pasty.

Maria's personal history reflects that of Silvia's, where she noticed how she was treated one way when first meeting people, but their attitudes changed when they found out she was Latinx. For both Maria and Silvia, once their racial identity became known, the discourse about them changed to a deficit view and their identities as successful students within the figured world of academic success was called into question.

In a related way, the impact of Colorism came up in one of the Black focus groups where Caleb indicated that he does not experience the same racially-charged situations as Anthony because he is much lighter than Anthony. Caleb is lighterskinned and called himself "half White." Conversely, Anthony called himself a 
"chocolate drop in a bunch of marshmallows," pointing out that it is hard to miss his very dark skin in a predominately light-skinned, White and Asian classroom. He believed this had led to him being targeted or noticed more immediately than other students for his behavior, especially if it is negative. For instance, when they are in the same class, other people tend to turn to Anthony first if there is a topic brought up in class that is considered a Black topic, such as slavery or Dr. Martin Luther King, Jr. Yet Caleb did not recount feeling that same pressure, which he felt was due to his much lighter skin. When viewed together with Maria and Silvia's examples, these stories demonstrate that, in the discourse about Black and Latinx students at CSHS, there is a clear distinction made between those students with lighter skin tone and those who are darker.

Microaggressions, racist jokes, and racist language. In all the groups, students painted a vivid picture of the daily racism that they faced at CSHS. There were multiple instances of microaggressions, racist jokes, and blatant use of racist language. The microaggressions took the form of assumptions others made about them or interactions that would not have happened to other ethnicities. For instance, Fernando, who identified himself as being Venezuelan, reported, "people find out I speak Spanish and they assume I'm from Mexico or things like that. It's just like, that's one country out of so many that speak Spanish, so that I don't understand." 
For another example, Anthony and Caleb talked about how some non-Black students would touch their hair, making them feel very uncomfortable. Caleb said, "I don't know, it's just weird to me... I just don't like people touching my hair. . don't do it unless I say you can." Anthony's response was a little sterner. "I'm not your pet. I'm not a sheep, so don't touch my hair." Also, the students expressed their frustration at being made to be the spokesperson for their entire actual or perceived race. Alisha explained, "They're up in history talking about slavery and they directly look at you like, boom! 'What do you think?"”

Another form of microaggression surfaced within their own friend groups by being used as a "shield," as Lionel described it, or "as a pass" as Alisha called it, for non-Black or non-Latinx students to make racist comments or jokes. Alisha said, "There's that Black person in the group, they use that Black person in the group to justify the things that they say and do." Brianna agreed, "They're like 'Oh, it's alright if I say it [racist joke or comment] because my friend is Black." In a different focus group, Silvia described her own experience with others thinking her friendship gave them the right to make racist jokes:

Unfortunately, I had a group of friends here ... and they're like "Oh, did you do swimming when you were younger?" I was like "Yeah, I was on the swim team and I used to swim every summer from kindergarten to fifth 
grade." .. I I was like, "I excelled really, really hard in swimming. I tried really hard." And they're like, "Oh, it's probably because you swam here." [when she supposedly immigrated from Mexico] I'm like, "Are you kidding me? No! I worked really hard to be really good at swimming!" So, it's just things like that where people think they can just joke around and say really racist jokes because they have a friend who's multicultural, who's not American or not White. And so, they think that they have the privilege now to be like, "I can joke about this and not feel bad because my friend is such and such."

That these instances were detailed by separate focus groups speaks to the deeprooted nature of the racialized discourse about Students of Color at CSHS.

Within the discourse at CSHS, these blatant jokes and continued marginalization of Black and Latinx students has created an environment that allows for even more flagrant racist occurrences. Both Black focus groups gave several instances of White and Asian students using the "N word" with impunity. Alisha related a story within one of her classes where a non-Black student used the "N word":

I was in my history class and we're giving presentations . . . everybody has their own topic ... within the time period ... and in my group, this Asian 
chick has the nerve, the nerve, the audacity! So nowhere on the slide did it say "nigger," "negro," nothing. It said Black or African American. They [her group members] made sure throughout... unless it was like the "Negro Leagues." That was the only thing that I could remember that had the "N word" in it. And I don't know what she was trying to do, was she trying to impress or look smart and she was reading off the slide and she even paused. Instead of saying "an African American" she said "the Niggers" and I said, "Whoa!" I looked over and everybody like looked at me and then looked at her and like you... it was like the weight in the room and she just kept on going like it was nothing. She was like "Yeah, you know." And she was with this tone that was like, "I know it all" and, "I said this and I did this." And I was really looking like...I just wanted to hurt her, I did and like, that is not okay!

Anthony described a time that he was called the "N word" with a "hard r" during class by a White classmate. "This girl, she did it so slyly and like, hateful. . Y Yeah, it cut me deep." Then adding further insult, he felt that the administration did not believe him and that the teacher, who did not hear him being called the name, minimized the severity of the situation. He was left feeling invalidated and pushed aside, especially since he then decided he needed to change some of his classes to 
avoid being with the girl who called him the name. Further, not all the classes he had with her were changed, so he had to cope with her in class. He noted how difficult it was for him to stay focused in the one class he still shared with her. In fact, over time these instances have interfered with his schooling in general:

Anthony: I was called the $\mathrm{N}$ word in some form or fashion every day, every school day for the solid three or four years. . . from like 6 th to 9 th. . I I guess it just kind of weighs you down after a while, like picking up on these things. It's not any one incident that'll get you down, but...

Interviewer: The weight of all of them...

Anthony: Yeah.

When recounting the story, Anthony's mistrust of the administration and teacher is clear and that he has no faith that they will act to support him. Similarly, when I asked Alisha if the teacher had done anything about the girl using the derogatory name in front of the whole class, she said, "The thing is, the teacher didn't say anything."

Adult bias. Alisha's story serves to highlight the absence of adult action or intervention in the face racism, which is a striking part of the discourse that the Students of Color have about the academic world at CSHS. Many of the students 
described racist comments and jokes begin made by fellow classmates that either went unnoticed or ignored by teachers. The students expressed feelings of mistrust in most adults on campus because they felt they would get no support in stopping the racism. Students were also able to recall adults being directly biased or racist themselves, which added to this mistrust. One such example came from the conversation with Regina and Francisca, two Latinx students.

Regina: There have been times when I'm in class and I just think to myself "Wow, that teacher really shouldn't have said that out loud."

Interviewer: How does that make you feel in the class when the teacher does that, or doesn't do that? Like if they don't say something when the students say something, or if they do say something that, like you said, in your head you're questioning. How does that make you feel in that classroom?

Regina: I feel embarrassed, I also feel kind of like I've been put down.

Interviewer: By the teacher?

Regina: Yeah.

Interviewer: By the teacher? [to Francisca] 
Francisca: Yeah, I feel like I'm not being supported or helped, or I don't know if that's the right word, but I kind of feel weak kind of sometimes. It's like, "Okay, I'm being attacked kind of thing and they're not helping."

Across the focus groups, the students struggled to come up with staff members or interactions with adults who had a positive impact on them. This was especially true of teachers, as many of the students provided examples where the teachers' attitudes and behavior had been perceived as racist. As detailed earlier, Brianna was easily able to share a negative experience with one of her teachers who had such low expectations that the teacher expressed surprise at Brianna doing well academically. In another example, Joaquin and Gabriel talked about how teachers made assumptions that they would eventually miss class or that they had missed more class than they actually had.

Joaquin: I'll miss a day of class, right? . . then I come back the next day, I go up to the teacher and ask what we missed and they're like "Oh, you didn't come to class yesterday?" But they give me this look like "Oh, I knew eventually you wouldn't come to class." Or they already think that my goal as soon as I step into the class is to cut as much of the class 
as possible. Or there are even some teachers that get surprised if I walk up to them and I'm like "Yeah, so I didn't do so good on this test, what can I do about it?" Because they're like "Oh, you care about your grade? That's strange."

Gabriel: $\quad$ Like one time, I missed class because I had to go to a funeral and I asked the teacher "What did I miss?" And she was like, "Oh, well, maybe you should come to class more." That was the first time I ever missed class and then when I told her "I'm sorry, I was at a funeral." She stood quiet, she didn't respond or anything. And she just told me right away what we had done.

Other examples included both the Black and Latinx students talking about being questioned by teachers or campus security when they were in common school areas during class, even when they had a legitimate reason for being there. Yet, the students observed, when White and Asian students were in these same areas, staff did not question them.

Overall, the students discussed how uncomfortable they felt if ever they needed support from most adults at school. In contrast, these students described family and friends as their primary source of motivation and support. This pattern 
emerged clearly across all the focus groups. At best, teachers were viewed as begrudgingly offering support. Regina disclosed that she did not like feeling like (in her words) "an obligation," so she avoided asking teachers for help.

Identity/World Making. A student's identity within the figured world of academic success is developed through a host of recurring discourses they engage in while invoking the multitude of cultural artıfacts. As they pick and choose from the possible positions within the figured world, students use this positionality to create room for their own identity, or a space of authoring. When harnessed strategically, students can use the space of authoring to design a figured world of their own making. World making gives students the ability to further shape their own identity (Holland et al., 1998; Seglem \& Garcia, 2015). While identity construction occurs throughout the interactions with artifacts and within the discourses that frame the daily lives of the students within the figured world, it is discussed in this section as a separate element to highlight the identities that these successful students have been able to create and maintain in the racialized world of academic success at CSHS.

Pride in themselves and their racial/cultural identity. Throughout the focus groups, the students felt pride in themselves and the work they had done. They collectively took their positions as successful students within the figured world of 
academic achievement, sometimes directly. For example, Gabriel proclaimed, "I know I'm intelligent." Other times it was indirectly, such as when they narrated a story about how hard they worked or what they had accomplished. Primary to this assurance in their academic identity was their racial or cultural identity. Alisha stressed that being Black to her was:

In a way, an advantage. It sounds weird, but, as an advantage, but...I feel like because I'm Black, I have like a privi. . . [stops, then restarts] Like, so we overcome different things than other people overcome and so that makes us -- I don't want to say stronger -- but it makes us more resilient and we know how to handle certain situations better and in different ways. Similarly, Silvia takes pride in identifying very strongly with being both Mexican and Nicaraguan, pointing to her father as the reason why:

My dad has always been very proud, coming from a country that had a revolution ... He still ties himself back to Mexico and to Nicaragua because he spent a lot of time in Mexico, too. And every time we go anywhere, we go to a museum or something. He's like, "See, don't let anybody tell you that you don't belong here, because this country was founded on immigrants and everything." He's like, "Look at all these people. You belong here just as much as they do." 
These two examples are some of the more explicit examples of the pride that students have in their racial and cultural identities.

Proving them wrong. With many of the other students, their pride was evidenced through the stories they told, especially as they described the way they channeled their strong identity to respond to the racialism at CSHS. As an illustration of this, Trent insisted, "I have no problem being Black; it's mostly I see like other people have problems with me being Black." The examples the students gave revealed that they had already begun to "rearrange, reword, rephrase, reorchestrate different voices. . ." (Holland et al., 1998, pg. 183), therefore claiming a space of authoring within the racialized figured world of academic success. By doing this, they created space for their own achievements. Maria proclaimed:

And so I'm just fueled by this undying anger, because I'm feisty. Just to prove people wrong. . . and it's very easy to do that because people are always wrong about that sort of stuff and they should just stop with the prejudices and stereotypes.

Samantha agreed when she said "People expect you to do poorly because it's a high class or something and as soon as you get a good grade, it's kind of like you enjoy 
that look of surprise or confusion." Joaquin explained further, discussing how his response has affected his success:

If everyone already expects me to, even subconsciously . . . not do great in school, I get a little kick out of actually walking in and being a pretty good student. . . that's how it has affected my education so far.

Anthony tied his response to racial bias back to his definition of success:

There is not the same expectations off of inherent biases and judgments for youth of Color. The less you expect, the less you think of that person, so success for me is changing people's opinions and making them see you on the same playing field.

What all these examples have in common is how the students used their power to author their own reality, thus taking part in the process of world making. Their response was to work harder in the face of bias and construct their own version of success.

\section{Finding Solutions}

Capturing the experiences of the Black and Latinx students at this predominately White and Asian high-achieving suburban high school lays a foundation for the equity work needed to address the racism and bias affecting their education. However, a more active stance is called for, which is why I asked them 
to provide possible solutions and ways to address the culture and climate of the school. In each of the focus groups, the students stressed the importance of openly talking about that the ideas of race and diversity. Caleb said, "That would help more than just not approaching and talking about it at all ... and not just in history classes, but just like all around in every class." Anthony took it a step further and suggested that the entire school have "An open forum once a month, a place for people to talk about issues like maybe sexism, racism, stuff like that." Francisca agreed when she said, "We should have more activities that are actually focused on the different nationalities, different races ... so we could actually learn about being connected, even though we're different races, different cultures . ..." She felt these types of activities would promote conversations to help people become more aware of the impact of their words and actions on others. Fernando asked an incisive question to make his point:

Why is the average Joe a White person, you know? ... the fact that people think it's okay to use the word Mexican when they really mean the word Latino to refer to anybody from Latin America. That's a problem . . . I feel like we don't talk about race a lot and I think we should.

On the other hand, there was also a desire expressed to not single minority students out. Regina named a CSHS college-going support program as problematic 
because of what she saw as its over-emphasis on minority students. She thought that the focus should be broader and include anyone who wanted the help to get to college. In a different focus group, Joaquin agreed, clarifying:

So there's this thing where people want more support of minorities, but I think that pushes the minorities into being isolated. I think the support or focusing on supporting them, a minority group or minorities in general isn't the best thing you can do because then people are like "Oh, they have to get support in order to be good."

Samantha backed up Joaquin's response by summarizing with what she thought was the solution: "We don't always need support, we just need teachers to realize that we can do APs and Honors." All of her group members (Maria, Gabriel, and Joaquin), enthusiastically supported her statement.

The importance of adults who believe in them and understand their struggles at CSHS was a key issue also brought up in other focus groups. For example, Anthony and Caleb communicated the importance of trusted adults who could support and talk to Students of Color about growing up in a predominately White community. However, they could only name a few such adults on campus. One adult who was named across all of the focus groups was Tamika Dyson, a school counselor and coordinator of a program called Avenues to Success. This 
program aims to support the academic success of underrepresented students, especially the steps needed to apply to college. In their conversation, Christopher and Silvia revealed that they seek her out, even though she is not the assigned counselor for either one of them.

Christopher: I love Ms. Dyson. She was the first person I saw when I transferred here. She helped to make the transition here really smooth, she was really funny ... I remember she helped me during the application process for college. I didn't know where to go, so I went to her . . . But she's really probably the nicest counselor I've had and she's a lively kind of person and I just like being around her. ...

Silvia: $\quad$ Yeah, Ms. Dyson is like another one of my favorite people. She's so nice. Like every time my counselor is busy or I can't reach my counselor, she would always be like "Oh, what can I help you out with?” . . I also just wrote her a letter once I got into college, because I was just like, "You've helped me so much at CSHS" and she's been somebody that I know I could always go to if like somebody else isn't there; then I'm like, "Ms. Dyson is there, she loves me!" 
When other students brought Ms. Dyson up, they spoke about how she would follow up with them about their classes and was approachable. Alisha insisted the she was "Actually kind of happy to have [Ms. Dyson] be on my butt about stuff ..." because her help was vital in Alisha's eyes to her academic success. Anthony said she had a "motherly nature" with him. Further exploration revealed that Ms. Dyson was not Anthony's assigned counselor, so I asked him why he went to her instead of his counselor of record. He stated, "Cultural similarities, that's why I go... She can relate to some of the stuff that I go through as a Black man in America." Tiana concurred with him from her own perspective:

I guess she knows, I don't know how to explain it, but I guess she understands me more ... And I think sophomore and junior year they changed my counselor, because they had to do alphabetical or something. So, I had to have my dad email the principal and go through all of that to have her back because I was just comfortable with her. So, I just made sure I got her back.

Tiana's actions reinforce the strong feelings she has about needing Ms. Dyson's support. Having a counselor with the same cultural background is clearly important enough to both students that they were willing to make an extra effort to get Ms. Dyson's help. 
I then asked the students how to this lack of trusted adults on campus could be fixed. Alisha proclaimed, "I'd like to see some black teachers, feel me?" Brianna followed Alisha by describing the need more broadly:

[Someone]that like looks like you. Like representation, I feel like is important ... it just kind of puts thing in perspective like "Oh, I can become this and that" ... Like if we had a teacher who kind of looks like you and they understand everything, I think you would be more open to just going to them for help or just anything that you need.

If a teacher was not actually from the same ethnicity, race, or background, Anthony felt that a teacher who makes an effort to be aware of racial and culturally issues and shares that with their students is a benefit to the campus. This need for culturally awareness was reiterated in other focus groups. Regina and Francisca indirectly discussed this earlier when they told their stories about teachers who said things they should not have. Culturally sensitive teachers would have avoid making the biased statements.

Furthermore, Brianna and Alisha shared how tired they were of dealing with classroom lessons and discussions focusing on narrow examples of Black history or literature. For example, Brianna said, "The textbooks only tell like, just the one part about slavery. .. there's more to Black history than just the slavery part. Like there 
is actual culture and things like that that never get taught." Expanding the curriculum and lessons would require teachers to become more culturally aware.

Some of the students pointed out other ways that the curriculum and instruction in the classrooms could become more responsive to the students and counter the high-pressured environment at CSHS. One focus group hit upon the need to structure classrooms around alternatives to summative assessments that just focus on the end result of the unit. The students described how only having highstakes tests at the end of a unit created a focus on the grade and took away from their love of learning. Instead, they suggested having projects and smaller formative assessments that allowed them to see what they were learning as they were going along. Joaquin gave an example about one of his classes that tried this type of hands-on approach, "So, it was less of trying to memorize things and it was more trying to do things and actually show that you know how to do stuff by doing it, instead of bubbling in some answers on a test." Maria talked about a class that was different from the others she had: "[All the students in the class] really like it because it's a lot different than how teachers are teaching now, but it was really helpful because it's not just tests. Tests aren't the emphasis. The emphasis are projects and stuff." 
Taking her suggestions beyond the classroom to the structure of departments, Silvia expressed her concern that lack of alignment within math specifically created barriers to students in accessing the curriculum for a couple of reasons. One reason she mentions is that she has seen students end up being placed in the wrong courses because there is not a better fit for them. Secondly, in her experience, once students are in the classes, teachers do not know how to respond to such a large range of abilities. She says:

I just don't think the teachers do a very good job of making sure that everyone is caught up and everybody's understanding the material ... I really hope that in the future it gets better or does something in a way that where every single student doesn't need a tutor in order to succeed in a math class.

Accordingly, creating greater alignment of the curriculum in departments and helping teachers to be better equipped to instruct mixed-ability level classes would give students improved learning experiences. Drawing on student experiences and insights such as this last one, chapter five will discuss the ways an anti-racist site leader can tackle the issues at a school challenged by a racialized culture like the one at CSHS. 


\section{Chapter Five: Discussions and Conclusions}

The No Child Left Behind federal policy had the effect of requiring all schools, including affluent suburban schools like Creekside High, to disaggregate their student achievement data. This reporting requirement has uncovered the glaring inequities in educational outcomes for suburban school's marginalized communities, especially Black and Latinx students. Most frequently, the disproportionately low achievement of Black and Latinx students within these schools has been labeled an achievement gap. This is a problematic term because the systemic inequities created by racial biases and which act upon the students are ignored, while the students are treated as having a deficit. Instead, framing the problem as an opportunity gap shifts responsibility back to the institution and places the moral onus on school leaders to create systems and practices that give students access to rigorous and meaningful educational experiences. With an assetbased foundation firmly in place, school leaders can then move forward in acting to ensure all students have access to rigorous and relevant learning experiences.

The fundamental purpose of this research was to uncover the lived experiences of successful Black and Latinx students in a majority White and Asian high-achieving suburban high school. This research expands the literature by centralizing the voice of successful Black and Latinx students in the decision- 
making process of suburban school administrators who aspire to be anti-racist leaders. Leadership decisions are regularly made in isolation from the very individuals most affected by those decisions. What this study works to do is demonstrate a way for leaders to consider the experiences of students who are often left out of the conversation where policy and practice are shaped. The use of focus groups deliberately shifted the power from myself, as the White site leader facilitating these discussions, to the Youth of Color in the focus groups, so that the students' opinions and ideas could take prominence. After exploring philosophical connections to the findings, a set of recommendations grounded in the suggestions of the students is provided. These action steps are further explained and clarified with examples from my own practice.

\section{Interpretation of Findings}

This study aimed to answer the following research question: What are the experiences of successful Black and Latinx students at a high-achieving, predominantly White and Asian suburban high school? This study expands the literature by centralizing the voice of successful Black and Latinx students in the decision-making process of suburban school administrators who aspire to be antiracist leaders. Leadership decisions are regularly made in isolation from the very individuals most affected by those decisions. What this study works to do is 
demonstrate a way for leaders to consider the experiences of students who are often left out of the conversation where policy and practice are shaped.

A finding that had profound impact was how relentlessly racialized the figured world of academic success is for the Black and Latinx students at CSHS. For these students, academic achievement is inexorably linked to their racial identity and their coping mechanisms for navigating the high-pressured figured world were further shaped by their need to compensate for the racialized world they were also having to navigate. As a school that prides itself on being open and diverse, much like the suburban high school that Modica (2015) studied, the students of Color at CSHS had to contend with a discourse that simultaneously reinforced negative racial biases and denied that the racial biases existed at all.

Given that the identity of successful student within the racialized world of academic success at CSHS excludes Students of Color, they have found a way to persist while maintaining their own sense of self. Through the generation of a double consciousness (Bruce, 1992), the Black and Latinx students have effectively built another world for themselves, one where Students of Color can create their own definitions of what it means to be successful specific to their ethnic or racial identity. The Black and Latinx students are acutely aware of their subordinate position with the world of success at CSHS, so this second, or double, identity 
provides them with a sense of equity and power denied by the identity imposed upon them by the figure world at CSHS (Bruce, 1992).

Needing to construct alternate identities to contend with the deficit narratives ascribed to them by the majoritarian discourse requires a tremendous amount of strength (Black, 2007). Students are simultaneously tasked with meeting the challenges presented by the high-pressured world of academic success and actively resisting being positioned as incapable students who need help to obtain the goal of being a successful student. Thus, while conceiving of an identity of success for themselves effectively counters the prescribed negative mantle, the strength-based consciousness must be maintained against the racist onslaught on a daily basis. Double consciousness highlights the active stance that the students take to reshape the world from one figured for them to one figured by them (Bruce, 1992). It validates the cultural wealth of the various racial identities within the term Students of Color and demonstrates the common experiences of Black and Latinx students as they contend with the dominant White norms and privileges (Black, 2007).

\section{Implications, Significance, and Praxis}

In the equity report produced by the Golden Valley Unified School District's Diversity Development Advisory Committee (DDAC) five problem areas 
were identified, including some short- and long-term recommendations for addressing the areas based on a variety of data. While student voice was included in the data collection, the students were from across the district and the questions did not focus on one school in particular. Therefore, the DDAC's recommendations took a district-wide approach that were more general in nature. The problem areas identified in the district's report serve as a starting point for the recommendations provided in this chapter.

Where the DDAC's report and this study are in complete alignment is the commitment to the equitable access to rigorous educational experiences for all students. To ensure that the recommended structural changes and policy implementation truly do provide the desired equity for students, the planned actions of a site leader must be grounded in culturally responsive tenets (Gay, 1994; Ladson-Billings, 1995; Shields, 2009, 2010; Theoharis \& Haddix, 2011; Paris, 2012; Khalifa, et al., 2016). Primary to these tenets is focusing on the experience of the students. Anti-racist leaders who respect these students' expertise around how best to traverse a racialized academic world should, therefore, draw upon these students' strategies to create more equitable educational environments.

Culturally Responsive School Leadership. The four elements of Culturally Responsive School Leadership identified by Khalifa, et al. (2016) 
provide a clear framework for how to move from theory to practice at a school in real time. To highlight direction of influences from the outer to inner domains, the four elements will be addressed in this order: engaging students and parents in community contexts, promoting culturally responsive and inclusive school environments, developing culturally responsive school teachers and curriculum, and critical self-reflection. What follows is an explanation organized by these four elements that provides recommendations for anti-racist leaders who wish to create equitable educational opportunities for non-dominant cultural groups at their schools. At the start of each of the four recommendation sections is a chart of action steps suggested for that element. Some action steps can be undertaken immediately and must be, because there is an urgency to address the needs of current students. Other recommendations will take time, due to the complex nature of cultural change at a school and the need to ensure that these changes last. Therefore, shortterm, long-term, and on-going timeframes are identified for each recommended action step. The actions steps are organized in a recommended priority level to indicate which actions act as anchors for the remaining actions. A complete chart of these anti-racist leadership action plans can be found in Appendix B.

Engaging Students and Parents in Community Contexts. The way a school's culture and climate treats the families and communities of its students 
sends a clear message to the student about their own worth. The deficit view that schools hold about Communities of Color sets a tone that individuals from those communities are not valued members of the academic world of success at the school (Yosso, 2005; Khalifa, et al., 2016). The fact that Anthony, a Black $10^{\text {th }}$ grader, could only name a few teachers at CSHS who were aware of the challenges faced by a Black student at a predominately White and Asian school meant that the larger school community has not engaged his community in a significant way. When Alisha and Brianna, Black $11^{\text {th }}$ graders in a different focus group than Anthony, talk about needing representation, they are pointing out a lack of room made for the Black community in the figured world of success in which they dwell.

A Culturally Responsive School Leader approaches all families and communities as having strengths and worth so as to open the door to meaningful interactions for everyone involved. If the intent of the interaction is to support, but the interaction still contains the message that the academic world of success is limited to only certain races, then the families will hear that they are not wanted. A Culturally Responsive School Leader aligns their actions with their anti-racist intent and that provides the foundation needed to welcome families and communities while giving their staff experience with the non-dominant cultures of the school. When staff interact positively with the families and communities of students, their 
actions lead to the understanding that Anthony had been searching for to no avail (Hynds, et al., 2016; Khalifa, et al., 2016).

Table 2:

Engaging Students and Parents in Community Contexts

\begin{tabular}{|l|l|c|}
\hline \multicolumn{1}{|c|}{ Action } & Timeframe & $\begin{array}{c}\text { Recommended } \\
\text { Priority Level }\end{array}$ \\
\hline $\begin{array}{l}\text { Build community communication plans } \\
\text { into all action plans at a site, including } \\
\text { site action/improvement plan, school } \\
\text { system development, program } \\
\text { development, course development, etc. }\end{array}$ & Long-term & First \\
\hline $\begin{array}{l}\text { Use district resources to tap into pre- } \\
\text { existing lines of communication (e.g., } \\
\text { communications directors or district- } \\
\text { level minority parent groups) and build } \\
\text { on what is already there. }\end{array}$ & Short-term & Second \\
\hline $\begin{array}{l}\text { Facilitate parent groups for } \\
\text { underrepresented communities. }\end{array}$ & Short-term & Second \\
\hline
\end{tabular}

Community connection recommendations. Through this research, I have

developed a deeper appreciation of the impact that a lack of interaction with marginalized communities has on school culture. The students described a feeling of isolation and a separation between them and the majority groups on campus. From their stories, it became clear that they felt that the figured world of success did not value or welcome individuals from their race or community. For a school like CSHS that has such a small number of non-dominant communities, this can be especially challenging because a site leader has so many obligations and it is easy 
to lose sight of lower profile responsibilities. Additionally, in affluent schools, the parent communities with the most agency and loudest voice often drown out the communities with smaller numbers. Therefore, it is imperative that a Culturally Responsive School Leader first take deliberate steps to include historically underrepresented families and communities when developing site action/improvement plans, school-wide systems, programs, or courses.

A concrete example of the importance of including families and communities at the planning stage of programs is what happened at CSHS with the launch of AVID, a program aimed at supporting our historically underrepresented students. As our team began the roll-out, the recruitment of students did not go as easily as we thought it would. In order to get better results, we decided to contact parents directly to discuss the program. As I reflect on this research, I realize that incorporating the voice of the families on the planning side would have helped make the recruitment more successful initially, rather than having to fix it afterwards.

When making these plans, leaders also need to collaborate closely with district support people, such as a communication director or outreach coordinator, to tap into pre-existing lines of communication and build on what is already there. In GVUSD, there is already an equity-focused group (Diversity Development 
Advisory Committee) made up of district and community members. Rather than searching for connections on my own, I could reach out to this group and get help in talking to individuals from the local communities.

Involving district resources would allow a site leader to immediately begin to facilitate the creation of more parent groups, specifically ones that represent marginalized communities. At CSHS, while there is the official Parent, Student, Teacher Association (PTSA), parents have created groups for their own communities, such as the Chinese Parent Network. Due to the state law requiring an English Language Advisory Committee, Latinx families were brought together by the school and they decided to create a Latino Parent Network. What I see lacking is a Black or Pacific Islander Parent Network. To my knowledge, neither community has been invited to create such a group and overtures from the school to include these communities in particular have not occurred. The first step will be to contact district supports to find out if there are community leaders I can talk with. These community leaders can help me become connected to parents who may already be taking action at the school. Also, our own school outreach counselor and parent liaison will have insights into ways to be more inclusive with the marginalized communities. I would also need help with designing any events we may plan so that events are truly welcoming. This may mean exploring different 
event times or locations. By normalizing the presence of community and family members from all racial groups, the figured world of success at CSHS will be opened wider and truly give room for everyone to fully participate.

Promoting Culturally Responsive and Inclusive School Environments. For the students living in and being the object of a racially-based deficit mindset, their alienation from the school culture is palpable. It is not enough to say we are an open and inclusive campus. When the actions of the adults repeatedly clash with this proclamation, the students quickly lose trust. When discussing the instances of microaggressions and racist language directed towards them, the students indicated a lack of adult intervention. Whether through inattention or active bias, the racial hierarchies are reinforced within the figured world at CSHS by the very people students are relying on to support their learning.

Table 3:

Promoting Culturally Responsive and Inclusive School Environments

\begin{tabular}{|l|c|c|}
\hline \multicolumn{1}{|c|}{ Action } & Timeframe & $\begin{array}{c}\text { Recommended } \\
\text { Priority Level }\end{array}$ \\
\hline $\begin{array}{l}\text { Model a social-justice mind-set in } \\
\text { everyday practices. }\end{array}$ & On-going & First \\
\hline $\begin{array}{l}\text { Develop shared leadership, by building } \\
\text { capacity in others and demonstrating } \\
\text { commitment to anti-racist ideals. }\end{array}$ & On-going & Second \\
\hline $\begin{array}{l}\text { Provide professional development } \\
\text { targeted at racial inequities, privilege, } \\
\text { and bias. }\end{array}$ & On-going & Second \\
\hline
\end{tabular}


School culture recommendations. First and foremost, an anti-racist leader must consciously orient all of their actions towards social-justice and equitable outcomes. Their everyday practices must reflect the anti-racist ideals that they wish to permeate the culture and climate of the school. Each day, a school leader has resources of time, people, and money at their disposal; how they choose to utilize these resources speaks to what they value. Examples include who a leader meets with or which meetings they attend, how quickly they respond to emails or other forms of communication, how the site budget is allocated, and the people hired for open positions. Each of these situations is an opportunity for a leader to model the equity and anti-racist ideals they wish to foster in others.

Modeling is just the beginning, because transforming a school's underlying racially biased culture demands the involvement of the whole school (Smith, 2005; Quantz et al., 1991). The idea of distributed leadership contends with two realities of the transformative process: 1) it is too much for one person to handle and 2) teaching every student needs to be a goal implemented by every group member to promote buy-in (Noonan \& Renihan, 2006). In addition, shared leadership acknowledges that a single person is not capable of knowing all there is to know about the multiple challenges a school leader must contend with on a continuing basis. Critically distributing the responsibilities while keeping the shared purpose in 
mind is a clear answer to this challenge (Noonan \& Renihan, 2006; Jacobs \& Kritsonis, 2007).

What this means in practice is that other stakeholders, such as teachers, staff, parents, and students, need to be actively involved in all decision-making processes. Seeking disparate voices and inviting them to be a part of decisionmaking teams is a key component of a real shift to an equitable school environment. By doing this, the leader is building the capacity of others to be leaders in their own right who are now capable of instigating change in areas where they perceive inequities (Jacobs \& Kritsonis, 2007). Input from all stakeholders can also come in the form of surveys, especially when the responses are disaggregated by sub-groups, including race, gender, socio-economic status, etc. Whenever possible, the site leader should turn the facilitation of a decision-making body over to a teacher or parent leader who shares the anti-racist ideals so that others can witness the shift in the power dynamic. Stepping back and becoming a participant in the process allows the leader to endorse the worth of the goal from another perspective and demonstrates a willingness to lead from behind. True democracy comes from the inside out, so including everyone and maximizing their strengths promotes the democratic ideals being protected by the CRSL (Quantz, et al., 1991; Ruebling, et al., 2004; Noonan \& Renihan, 2006; Khalifa, et al., 2016). 
When asked for their recommendations, the student participants unanimously suggested facilitated meetings for students where everyone could interact with a wider variety of classmates in order to learn to appreciate the diversity on campus. They also suggested that some of the meetings include teachers and other staff members so that the entire school community could benefit from a new appreciation. To accomplish this task appropriately requires more than making space for these interactions. Jumping into discussions about difficult topics such as bias, regardless of the cause, would be foolish and counterproductive. Rather, it means that the groundwork needs to be done with the adults on campus first. Professional development targeted at the issues of racial inequities, privilege, and bias on campus is a necessary part of this cultural shift. Through the introduction of these topics embedded within the staff meetings and training sessions, teachers and staff would then be made more aware of the racialized climate on campus. The following section provides recommendations on how to tie this work into what is happening in the classroom.

\section{Developing Culturally Responsive School Teacher and Curriculum.}

Supporting a school site's shift from deficit thinking to a strength-based model requires the implementation of culturally-aware teaching methods and assessments that are scientifically-based (Ishaq \& Kritsonis, 2009). Culturally Responsive 
Education (CRE) includes the development of the teachers and students in their awareness of their own cultures so as to build a positive school and classroom identity and grow relationships that support student growth (Brown-Jeffy \& Cooper, 2011) The purpose of this professional development needs to be aimed at providing staff and teachers with the skills necessary to deliver an equitable education, encompassing the varied students in the school. Developing buy-in is crucial, meaning that the leader needs to explain the benefits of this type of instruction, from reduced disciplinary issues and lowered student drop-out rates, to increased interest in and engagement with the curriculum (Smith, 2005). Once the training about CRE and culturally-sensitive instructional methods are delivered to the educators, equally important is the continued support they will need to develop the system of equity in their classroom (Garcia \& Guerra, 2004). New ways of teaching cannot be left to one person in isolation to duplicate; continued and targeted support is needed.

Table 4:

Developing Culturally Responsive School Teacher and Curriculum

\begin{tabular}{|l|c|c|}
\hline \multicolumn{1}{|c|}{ Action } & Timeframe & $\begin{array}{c}\text { Recommended } \\
\text { Priority Level }\end{array}$ \\
\hline $\begin{array}{l}\text { Build a guiding coalition of teacher } \\
\text { leaders to drive the evolution to } \\
\text { Culturally Responsive Education. }\end{array}$ & Short-term & First \\
\hline $\begin{array}{l}\text { Provide time for teacher collaboration } \\
\text { aimed at developing Culturally }\end{array}$ & Short-term & Second \\
\hline
\end{tabular}




\begin{tabular}{|l|c|c|}
\hline Responsive curriculum and instruction. & & \\
\hline $\begin{array}{l}\text { Provide professional development to } \\
\text { address inherent biases, deficit-thinking, } \\
\text { and culturally-responsive, research-based } \\
\text { instructional practices and curriculum. }\end{array}$ & On-going & Third \\
\hline $\begin{array}{l}\text { Provide data-driven feedback and } \\
\text { evaluation targeted at racial inequities, } \\
\text { privilege, and bias. }\end{array}$ & On-going & Third \\
\hline $\begin{array}{l}\text { Connect district equity initiatives to the } \\
\text { classroom. }\end{array}$ & $\begin{array}{l}\text { Short- and } \\
\text { long-term }\end{array}$ & Fourth \\
\hline
\end{tabular}

Culturally Responsive Education Recommendations. To address the students' call for school-wide conversations and acknowledgement of racism in the school, there is a need for educators to recognize systemic inequities based on race and intentionally make the classroom a space to question and challenge those inequities. It is insufficient to simply put into practice teaching strategies that support diverse student populations. An effective leader of a school constantly evaluates programs and initiatives. Once again, however, this cannot be done in isolation. To direct the school towards culturally responsive methods of instruction, the leader will need to build the capacity of all members of the leadership team to effectively assess the efficacy of programs and curriculum implemented schoolwide (Noonan \& Renihan, 2006; Ishaq \& Kritsonis, 2009). Department heads and teachers on special assignment (TOSAs) need to be working with teacher teams and individuals to make sure that teachers understand the connection between instructional goals and outcomes. Additionally, they need to explore and utilize the 
many types of assessments available, as well as know how to use assessment data to increase instructional effectiveness that addresses inequitable, racially-based outcomes (Noonan \& Renihan, 2006).

These teacher leaders should become the face of professional development. Giving space to staff members who share the equity vision and are already well regarded by their colleagues goes a long way in earning buy-in from the rest of the staff. Teacher leaders are in the unique position of understanding what their specific subject area needs to do to address the racialized learning environment with their classrooms. This means that the school leader needs to cultivate the teacher leaders strategically, making room for diverse racial and subject area teachers to play a part in the ongoing evolution of the school culture and climate. This diversity will help to orient teachers to the ideas of race and racism within the subject they teach and deepen their ability to recognize and respond to inequitable outcomes within their classrooms.

Engaging the teachers in targeted conversations about researched-based, culturally-responsive educational practices means providing time for this collaboration. At CSHS, collaborative time is built into the bell schedule, allowing staff space to enter into the conversations about problems of practice during that time every week. Additionally, time should be made within the school day to allow 
teachers to observe their colleagues practicing the strategies that they discuss in their collaboration time. Dedication of time and money is required to make this happen, so the school leader has to plan for this early in the school year.

The role of the school leader is to continue to facilitate teacher learning by providing professional development on school equity trends, current research, and culturally-responsive models of instruction. The school leader then has a responsibility to ensure that these topics are part of the feedback and evaluation process during the school year. If professional development is given to the staff, an expectation should be set that it is applied in their work. This can be accomplished through giving specific assignments in the professional development, along with concrete timelines for completion. Additionally, planning and reflecting conversations with teachers during evaluations should include discussion of site and district equity goals. As these conversation topics become more normalized, the aim would be to start including specific information about student success in the individual teacher's classroom, including a breakdown of the outcomes for racial sub-groups.

The foundation upon which this proposed professional development must rest is addressing the underlying assumptions that teachers and other staff make about students, especially those who are marginalized. Overcoming the 
unconscious prejudices, or implicit biases (Staats, 2016), of teachers is not a task easily accomplished. The district has begun this process by having every staff member in the district go through a training titled Unconscious Bias. This has been a multi-year plan with cohorts of teachers assigned to be trained at various times over several years. What has not happened, however, is the diffusion of the training into the classroom or teacher practice. There have been no tie-ins made to lesson planning or explicit activities for teachers to utilize in their classrooms, which means that the training is likely to remain superficial and not change actual teaching practice (Elmore, 2008). The steps that an anti-racist leader can are take to fix this oversight is to work with the district leaders to have all of the school site leaders in the district include the elements of the Unconscious Biases in their professional development plans. Part of each school site plan needs to include outcomes such as culturally-responsive curriculum development and resource building to be shared across the district. Utilizing the electronic databases already at the district's disposal would help to disseminate locally-created resources, thereby increasing their credibility in the eyes of the teachers. The initial step could be done within a school year and built upon each subsequent year.

Critical Self-reflection. Critical self-reflection is needed for a Culturally Responsive School Leader to be able to effectively address the external racial issues 
at a school. Being introspective about their own position and privilege within the educational system is a necessity before beginning purposeful and direct conversations about race and racism with staff (Smith, 2005; Shields, 2009, 2010; Theoharis \& Haddix, 2011; Khalifa, et al., 2016). Helping to cultivate that awareness in the staff is an important first step in attending to my students' request to create an environment where race can be talked about. Creating space for these discussions means that leaders can challenge any underlying assumptions their staff may have that lead to the continuation of damaging educational practices and norms. Having the skill to normalize these types of conversations means that social justice principals can assist their staff members in evolving their thoughts and actions towards their Students of Color. In the focus groups, the students stated that racism needed to be called out and discussed, especially by the adults. They described multiple situations where the teachers either missed blatant racism or ignored it by continuing to carry on as if nothing had happened. What the students were asking for was validation that their struggles were real. They know that by naming a struggle, it becomes real and it is then possible to take steps to change it.

Table 5:

Critical Self-reflection

\begin{tabular}{|c|c|c|}
\hline Action & Timeframe & $\begin{array}{c}\text { Recommended } \\
\text { Priority Level }\end{array}$ \\
\hline Develop an inquiry stance to interrogate & On-going & First \\
\hline
\end{tabular}




\begin{tabular}{|c|c|c|}
\hline $\begin{array}{l}\text { own biases and to serve as the foundation } \\
\text { for approaching the construction of } \\
\text { leadership actions. }\end{array}$ & & \\
\hline $\begin{array}{l}\text { Embed the conversations about race and } \\
\text { privilege into the discourse of the school } \\
\text { and wider community. }\end{array}$ & On-going & Second \\
\hline $\begin{array}{l}\text { Make it a priority to talk with non- } \\
\text { dominate groups of stakeholders. }\end{array}$ & $\begin{array}{l}\text { Short-term } \\
\text { and on- } \\
\text { going }\end{array}$ & Second \\
\hline $\begin{array}{l}\text { Lead staff in vital discussions about race } \\
\text { and privilege. }\end{array}$ & $\begin{array}{l}\text { Short-term } \\
\text { and long- } \\
\text { term }\end{array}$ & Second \\
\hline
\end{tabular}

Critical Self-reflection Recommendations. As a White, middle-class

educator who has endeavored to become a Culturally Responsive School Leader, I have come to recognize that it is not possible for me to critically reflect on something that I did not experience, and may not even realize exists. My own perspective precludes me from truly knowing what students from marginalized communities are facing. Listening to my Black and Latinx students talk about their racialized educational experiences at CSHS has provided me with a glimpse into their reality and thus has been powerful in shaping my internal dialogue (Matias, et. al, 2014). I am now able to check my decision-making process for gaps in equity in ways I was not capable of before. For example, when planning for the implementing an intervention, such as teacher support time or outside tutors, I used to approach it in a colorblind manner, meaning that I automatically took a "one-size fits all" approach. I had the unacknowledged assumption that all students would 
benefit from whatever process I put into place. Hearing the students express frustration about not having enough people on campus who understand or even recognize their daily experiences with racism has given me pause. In a practical way, it is important that an anti-racist leader take the time to talk with students, especially those that are part of the non-dominate cultural groups on campus. Carrying out a full-blown research protocol while actively leading a school is not necessary. Still, this study has reinforced for me the need to maintain the inquiry stance that has infused my experience with this dissertation. A leader needs to allow that critical and evidence-seeking point of view to serve as the foundation for approaching the construction of leadership actions.

One of the purposes of this dissertation was to assist me, and other aspiring anti-racist school leaders, in honing the ability to make these vital conversations a natural part of the school discourse. My own practice has already evolved as I have been challenged by the students in the focus groups to make the acknowledgment of intentional and unintentional racism a priority. Recently, a situation arose where several Black students brought a racially based problem to my attention. They had tried to discuss this issue with their club advisor (a White teacher), but they felt they were being dismissed. When I followed up with the teacher, she felt she had handled the problem in an unbiased way and then she said, "I do not talk about 
race." Because of my work with the focus groups, I could see how the teacher's handling of the situation was invalidating the experiences of the Black students and compounding their feelings of discrimination. When I explained this to her, the teacher was struck by how harmful her colorblind approach was and readily agreed to talk with the students with this new understanding. I am heartened that my own internal reflection upon my White privilege and position made it possible for me to discuss such a sensitive topic with this teacher in way that allowed her to evolve her own thinking. The next step will be to find ways to broaden these discussions school-wide. A Culturally Responsive School Leader takes on the responsibility of introducing the difficult topics to their staff and encouraging others to do the same.

\section{Recommendations for Further Study}

The recommendations for further study include researching the effectiveness of the action steps suggested in this dissertation. How effective each action step is depends on multiple factors, so the varying conditions under which the actions are implemented should be analyzed. For example, whether multiple schools in the district were involved in implementation of a specific action or if the school acted on its own. Of interest would be looking into how successful action steps are if the school does act without district support. 
Replicating this study at other suburban high schools with similar circumstances would be helpful in confirming these findings or revealing alternate outcomes. This would also aid to expand our understanding of the factors contributing to or potentially ameliorating the racially-biased school environment at high-achieving suburban schools. Having further studies could then lead to the development of a grounded theory about the experiences of Students of Color at predominately White schools.

Finally, examining the longitudinal effect of this racialized educational experience on these students could be accomplished by tracking them into their post high school college or career. Such a study could provide valuable information about the way their foundational schooling shaped their future success, including how surviving such a racialized environment effected their decisions about where to continue their education or what type of job they took.

\section{Conclusion}

As a member of the dominant group in education (White, female, middleclass), I am acutely aware that my life experiences have rarely matched those of the students I choose to serve. A deep commitment to the students and their futures has driven me to find ways to overcome this handicap. More than anything, I want the work that I do to result in opportunities for all students to select from a multitude of 
choices. Not knowing what some of my students are experiencing gets in the way of that outcome. I have learned to listen and ask questions, and what I have heard is that students want to be validated. They want who they are and what they have experienced to be valued.

As a person of privilege within the school, having a defined leadership role and being a member of the majority racial group, I recognize that I have the power to hold space to ensure that students are valued. Therefore, developing a study centered on the voices of Students of Color at this school where they are marginalized and are subjected to daily racism was important because it provides validity and confirms their worth. It also demonstrates that not only can definitive action to counterbalance this racism be taken by individuals who aspire to be Culturally Responsive School Leaders, but that crafting systems and practices that are based in equity and access for all students is possible. 


\section{References}

Allen, W., \& Griffin, K. (2006). Mo' money, mo' problems? High-achieving Black high school students' experiences with resources, racial climate, and resilience. Journal Of Negro Education, 75(3), 478-494.

Akom, A. A. (2003). Reexamining resistance as oppositional behavior: The nation of Islam and the creation of a Black achievement ideology. Sociology of Education, 76(4), 305-325.

Aronson, B., \& Laughter, J. (2016). The theory and practice of culturally relevant education: A synthesis of research across content areas. Review of Educational Research, 86(1), 163-206.

Andrews, D. C. (2009). The construction of Black high-achiever identities in a predominantly White high school. Anthropology \& Education Quarterly, 40(3), 297-317.

Barron, I. (2014). Finding a voice: A figured worlds approach to theorising young children's identities. Journal of Early Childhood Research, 12(3), 251-263.

Bernal, D. (2002). Critical race theory, Latino critical theory, and critical racedgendered epistemologies: Recognizing Students of Color as holders and creators of knowledge. Qualitative Inquiry, 8(1), 105-126. 
Black, M. (2007). Fanon and DuBoisian double consciousness. Human Architecture, 5, 393.

Bleske-Rechek, A., Lubinski, D., Benbow, C. (2004). Meeting the educational needs of special populations: Advanced Placement's role in developing exceptional human capital. Psychological Science, 15(4), 217-224.

Boylorn, R. M. (2010). Black kids' (BK) stories: Ta(l)king (about) race outside of the classroom. Cultural Studies $\leftrightarrow$ Critical Methodologies, 1-12.

Branch, G. F., Hanushek, E. A., \& Rivkin, S. G. (2013). School leaders matter. Education Next, 13(1), 62-69.

Brown-Jeffy, S., \& Cooper, J. E. (2011). Toward a conceptual framework of culturally relevant pedagogy: An overview of the conceptual and theoretical literature. Teacher Education Quarterly, 38(1), 65-84.

Bruce Jr., D. D. (1992). W.E.B. Du Bois and the idea of double consciousness. American Literature, 64(2), 299.

Cammarota, J. (2004). The gendered and racialized pathways of Latina and Latino youth: Different struggles, different resistances in the urban context. Anthropology \& Education Quarterly, 35(1), 53-74. 
Carter, D. J. (2007). Why the Black kids sit together at the stairs: The role of identity-affirming counter-spaces in a predominantly White high school. Journal Of Negro Education, 76(4), 542-554.

Carter, D. J. (2008). Achievement as resistance: The development of a critical race achievement ideology among Black achievers. Harvard Educational Review, 78(3), 466-497.

Chapman, T. K. (2013). You can't erase race! Using CRT to explain the presence of race and racism in majority White suburban schools. Discourse: Studies In The Cultural Politics Of Education, 34(4), 611-627.

Chapman, T. K. (2014). Is integration a dream deferred? Students of Color in majority White suburban schools. Journal Of Negro Education, 83(3), 311326.

Charmaz, K. (2005). Grounded theory in the $21^{\text {st }}$ century: Applications for advancing social justice studies. In N.K. Denzin \& Y.S. Lincoln (Eds.). The sage handbook of qualitative research (pp. 507-536). Thousand Oaks: Sage Publications.

Charmaz, K. (2006). Constructing grounded theory. Thousand Oaks: Sage Publications. 
Childress, S., Doyle, D., \& Thomas, D. (2009). Leading for equity: The pursuit of excellence in Montgomery County Public Schools. Cambridge: Harvard Education Press.

Cooper, C. (2009). Performing cultural work in demographically changing schools: Implications for expanding transformative leadership frameworks. Educational Administration Quarterly, 45(5), 694-724.

CSUMentor (n.d.) Plan for college - High school students - Eligibility index California residents. Retrieved February 7, 2016, from http://www.csumentor.edu/planning/high_school/cal_residents.asp

Darling-Hammond, L. (2010). The flat world and education: How America's commitment to equity will determine our future. New York: Teachers College Press.

Darling-Hammond, L. (2013). Inequality and school resources: What it will take. In Prudence L. Carter \& Kevin G. Welner (Eds.), Closing the Opportunity Gap (pp. 77-97). Oxford: Oxford University Press.

Dee, T., \& Penner, E. (2016). The causal effects of cultural relevance: Evidence from an ethnic studies curriculum. National Bureau of Economic Research. Retrieved from http://www.nber.org/papers/w21865

Delgado, R. and Stefancic, J. (2001). Critical race theory: An introduction. New 
York: New York University Press.

Diamond, J. B., Lewis, A. E., \& Gordon, L. (2007). Race and school achievement in a desegregated suburb: Reconsidering the oppositional culture explanation. International Journal Of Qualitative Studies In Education (QSE), 20(6), 655-679.

Dover, A. G. (2013). Teaching for social justice: From conceptual frameworks to classroom practices. Multicultural Perspectives, 15(1), 3-11.

Elmore, R.F. (2008). School reform from the inside out: Policy, practice, and performance. Cambridge: Harvard Education Press.

Esmonde, I. (2014). "Nobody's rich and nobody's poor ... It sounds good, but it's actually not": Affluent students learning mathematics and social justice. Journal of the Learning Sciences, 23(3), 348-391.

Espenshade, T. J., \& Radford, A. W. (2009). No longer separate, not yet equal: Race and class in elite college admission and campus life. Princeton University Press.

Fordham, S., \& Ogbu, J. U. (1986). Black students', school success: Coping with the "burden of 'acting white". Urban Review, 18(3), 176-206.

Friend, J., \& Caruthers, L. (2012). Reconstructing the cultural context of urban schools: Listening to the voices of high school students. Educational 
Studies: Journal Of The American Educational Studies Association, 48(4), 366-388.

Garcia, S., \& Guerra, P. (2004). Deconstructing deficit thinking: Working with educators to create more equitable learning environments. Education and Urban Society, 36; 150-161.

Gay, G. (1994). Coming of age ethnically: Teaching young adolescents of color. Theory Into Practice, 33, 149-155.

Gayles, J. (2005). Playing the game and paying the price: Academic resilience among three high-achieving African American males. Anthropology \& Education Quarterly, 36(3), 250-264.

Geiser, S. \& Santelices, V. (2004). The role of Advanced Placement and honors courses in college admissions. Research \& Occasional Paper Series: Center For Studies In Higher Education, 4(04), 1-29.

Gordon, B. M. (2012). "Give a brotha a break!": The experiences and dilemmas of middle-class African American male students in White suburban schools. Teachers College Record, 114(5), 1-26.

Harper, S. R. (2015). Success in these schools? Visual counternarratives of young men of color and urban high schools they attend. Urban Education, 50(2), 139-169. 
Hatt, B. (2007). Street smarts vs. book smarts: The figured world of smartness in the lives of marginalized, urban youth. The Urban Review, 39(2), 107-116.

Holland, D., Lachicotte, W., Skinner, D. C., \& Cain, C. C. (1998). Identity and agency in cultural worlds. Cambridge: Harvard University Press.

Hynds, A., Averill, R., Penetito, W., Meyer, L., Hindle, R., \& Faircloth, S. (2016). Examining the impediments to indigenous strategy and approaches in mainstream secondary schools. International Journal of Leadership in Education, 19(5), 534-556.

Irizarry, J. G. (2015). What Latino students want from school. Educational Leadership, 72(6), 66-71.

Ishaq, K. \& Kritsonis, W. (2009) School leadership makes a difference: A sociological perspective of effective strategic planning and integrating realms of meaning into school improvement. National Forum of Applied Educational Research Journal, 23(1 \& 2), 1-8.

Ispa-Landa, S. (2013). Gender, race, and justifications for group exclusion: Urban Black students bussed to affluent suburban schools. Sociology of Education, 86(3), 218-233.

Ispa-Landa, S., \& Conwell, J. (2015). "Once you go to a white school, you kind of adapt": Black adolescents and the racial classification of schools. Sociology 
Of Education, 88(1), 1-19.

Jacobs, K. \& Kritsonis, W. (2007) Strategies for implementing postmodern thinking for improving secondary education in public education in the United States of America: National impact. The Lamar University Electronic Journal of Student Research, 1-11.

Jayakumar, U.M., Vue, R. \& Allen, W. R. (2013). Pathways to college for young Black scholars: A community cultural wealth perspective. Harvard Educational Review 83(4), 551-579.

King, J. E. (1991). Dysconscious racism: Ideology, identity, and the miseducation of teachers. The Journal of Negro Education, 60(2), 133-146.

Khalifa, M. A. (2011). Teacher Expectations and Principal Behavior: Responding to Teacher Acquiescence. Urban Review: Issues and Ideas in Public Education, 43(5), 702-727.

Khalifa, M. A., Gooden, M. A., \& Davis, J. E. (2016). Culturally responsive school leadership: A synthesis of the literature. Review of Educational Research, $86(4), 1272-1311$.

Kohli, R., \& Solórzano, D. G. (2012). Teachers, please learn our names!: Racial microaggressions and the K-12 classroom. Race, Ethnicity and Education, $15(4), 441-462$. 
Ladson-Billings, G. (1995). Toward a theory of culturally relevant pedagogy. American Educational Research Journal, 32(3), 465-491.

Ladson-Billings, G. (1998). Just what is critical race theory and what's it doing in a nice field like education? International Journal of Qualitative Studies in Education, 11, 7-24.

Ladson-Billings, G. \& Tate, W. (1995). Towards a critical race theory of education. Teachers College Record, 97, 47-68.

López, I. H. (2006). Colorblind to the reality of race in America. The Chronicle Review, 53(11), B6-B9.

Madhlangobe, L., \& Gordon, S. P. (2012). Culturally responsive leadership in a diverse school: A case study of a high school leader. NASSp Bulletin, 96(3), 177-202.

Madriz, E. I. (1998). Using focus groups with lower socioeconomic status Latina women. Qualitative Inquiry, 4(1), 114.

Matias, C. E. (2013). On the "flip" side: A teacher educator of color unveiling the dangerous minds of white teacher candidates. Teacher Education Quarterly, $40(2), 53$.

Matias, C. E., Viesca, K. M., Garrison-Wade, D. F., Tandon, M., \& Galindo, R. (2014). "What Is critical whiteness doing in our nice field like critical race 
theory?" Applying CRT and CWS to understand the white imaginations of white teacher candidates. Equity \& Excellence in Education, 47(3), 289304.

Matute-Bianchi, M. E. (1986). Ethnic identities and patterns of school success and failure among Mexican-descent and Japanese-American students in a California high school: An ethnographic analysis. American Journal of Education, 95(1), 233-255.

Mayfield, V. M., \& Garrison-Wade, D. (2015). Culturally responsive practices as whole school reform. Journal of Instructional Pedagogies, 16, 1-17.

McGee, E. O., Alvarez, A., \& Milner, H. R. (2016). Colorism as a salient space for understanding in teacher preparation. Theory Into Practice, 55(1), 69-79.

McKown, C., \& Weinstein, R. S. (2008). Teacher Expectations, Classroom Context, and the Achievement Gap. Journal of School Psychology, 46(3), 235-261.

Miles, M. B., Huberman, A. M. \& Saldaña. J. (2014). Qualitative data analysis: A methods sourcebook (3rd ed.). Thousand Oaks, CA: Sage.

Modica, M. (2015). Unpacking the "colorblind approach": Accusations of racism at a friendly, mixed-race school. Race, Ethnicity And Education, 18(3), 396418. 
Diversity Development Advisory Committee (2015). Report to the board of education. Retrieved from Golden Valley Unified School district website (link removed at request of district to preserve anonymity)

Muller, C., Riegle-Crumb, C., Schiller, K. S., Wilkinson, L., \& Frank, K. A. (2010). Race and academic achievement in racially diverse high schools: Opportunity and stratification. Teachers College Record, 112(4), 10381063.

Noonan, B., \& Renihan, P. (2006). Demystifying assessment leadership. Canadian Journal of Educational Administration and Policy, 56, 1-21.

Nunn, L. M. (2011). Classrooms as racialized spaces: Dynamics of collaboration, tension, and student attitudes in urban and suburban high schools. Urban Education, 46(6), 1226-1255.

Oakes, J. (2005). Keeping track: How schools structure inequality. New Haven, Connecticut: Yale University Press.

O’Connor, C., Mueller, J., Lewis, R. L., Rivas-Drake, D., \& Rosenberg, S. (2011). "Being" Black and strategizing for excellence in a racially stratified academic hierarchy. American Educational Research Journal, 48(6), 1232 1257. 
Ogbu, J.U. (1991). Immigrant and nonimmigrant minorities in comparative perspective. In M. Gibson \& J. Ogbu (Eds.), Minority status and schooling: A comparative perspective (pp. 3-36). New York: Garland.

Ogbu, J. U. (2003). Black American students in an affluent suburb: A study of academic disengagement. Mahwah, N.J.: L. Erlbaum Associates.

Olszewski-Kubilius, P., \& Clarenbach, J. (2014). Closing the opportunity gap: Program factors contributing to academic success in culturally different youth. Gifted Child Today, 37(2), 103-110.

Omi, M. \& Winant, H. (1993). On the theoretical status of the concept of race. In Cameron McCarthy \& Warren Cricklou (Eds.), Race, Identity, and Representation in Education (pp. 3-10). New York: Routledge.

Orfield, M. \& Luce, T. (2013). America's racially diverse suburbs: Opportunities and challenges. Housing Policy Debate, 23(2), 395-430.

Paris, D. (2012). Culturally sustaining pedagogy: A needed change in stance, terminology, and practice. Educational Researcher, 41(3), 93-97.

Picower, B. (2009). The unexamined whiteness of teaching: How white teachers maintain and enact dominant racial ideologies. Race, Ethnicity and Education, 12(2), 197-215. 
Quantz, R., Rogers, J., \& Dantlet, M. (1991). Rethinking transformative leadership: Toward democratic reform of schools. Journal of Education, 173(3), 96118.

Rivera, G. J. (2014). What high-achieving Latino students need to apply to college: Environmental factors, individual resiliency, or both? Hispanic Journal of Behavioral Sciences, 36(3), 284-300.

Ruebling, C., Stow, S., Kayona, F., \& Clarke, N. (2004). Instructional leadership: An essential ingredient for improving student learning. The Educational Forum, 68, 243-253.

Ryu, M. (2015). Positionings of racial, ethnic, and linguistic minority students in high school biology class: Implications for science education in diverse classrooms. Journal of Research in Science Teaching, 52(3), 347-370.

Saldaña, J. (2013). The coding manual for qualitative researchers (2nd ed.). Thousand Oaks, CA: Sage Publications.

Santamaría, L. J. (2014). Critical change for the greater good: Multicultural perceptions in educational leadership toward social justice and equity. Educational Administration Quarterly, 50(3), 347-391.

Staats, C. (2016). Understanding Implicit Bias: What Educators Should Know. American Educator, 39(4), 29-33,. 
Saunders, J. M. (2012). Intersecting realities: A novice's attempts to use critical literacy to access Her students' figured worlds. Multicultural Education, 19(2), 18-23.

Seglem, R., \& Garcia, A. (2015). "So we have to teach them or what?": Introducing preservice teachers to the figured worlds of urban youth through digital conversation. Teachers College Record, 117(3).

Shields, C. (2004). Dialogic leadership for social justice: Overcoming pathologies of silence. Educational Administration Quarterly, 40(1), 109-132.

Shields, C. (2009) Transformative leadership: A call for difficult dialogue and courageous action in racialised contexts. International Studies in Educational Administration, 37(3), 53-68.

Shields, C. (2010). Transformative leadership: Working for equity in diverse contexts. Educational Administration Quarterly, 46(558), 558-589.

Smith, C. (2005). School factors that contribute to the underachievement of Students of Color and what culturally competent school leaders can do. Educational Leadership and Administration, 17, 21-32.

Solórzano, D.G., \& Bernal, D. (2001). Examining transformational resistance through a Critical Race and LatCrit Theory framework: Chicana And Chicano students in an urban context. Urban Education, 36(3), 308-342. 
Solórzano, D. G., \& Ornelas, A. (2002). A Critical Race Analysis of Advanced Placement Classes: A Case of Educational Inequality. Journal of Latinos and Education, 1(4), 215-29.

Solórzano, D. G. \& Yosso, T. (2002). Critical race methodology: CounterStorytelling as an analytical framework for education research. Qualitative Inquiry, 8(1), 23-44.

Steinberg, A. \& Almeida, C. A. (2008). Raising graduation rates in an era of high standards: Five commitments for state action [White Paper]. Jobs For The Future. Retrieved from http://files.eric.ed.gov/fulltext/ED500541.pdf

Theoharis, G. (2007). Social justice educational leaders and resistance: Toward a theory of social justice leadership. Educational Administration Quarterly, 43(2), 221-258.

Theoharis, G., \& Haddix, M. (2011). Undermining racism and a whiteness ideology: White principals living a commitment to equitable and excellent schools. Urban Education, 46(6), 1332-1351.

Urrieta, L. (2007a). Figured worlds and education: An introduction to the special issue. The Urban Review, 39(2), 107-116. 
Urrieta, L. (2007b). Identity production in figured worlds: How some Mexican Americans become Chicana/o activist educators. The Urban Review, 39(2), 117-144.

Yosso, T. J. (2002). Critical race media literacy: Challenging deficit discourse about Chicanas/os. Journal of Popular Film and Television, 30(1), 52-62.

Yosso, T. J. (2005). Whose culture has capital? A critical race theory discussion of community cultural wealth. Race, Ethnicity and Education, 8, 69-91. 


\section{Appendix A}

\section{Student Focus Group Protocol}

\section{Opening (To be modified for the second round)}

Hi, I'm Mrs. Wheeler. In addition to being an Assistant Principal here at Creekside High School, I am also a graduate student at SFSU in the Educational Leadership Department. You have been invited to this focus group because of the success you have achieved here at CSHS. I am interested in hearing about your educational experiences and your opinions about what success means and how it is achieved. The information discussed in this focus group is confidential and private, so please do not share anything outside of this group. I will ask that all of you confirm that you understand the confidential nature of this group. (Pause while they confirm.) Thank you.

You do not need to answer any questions that you feel uncomfortable with. I have provided each of you with a journal so you can write down any thoughts or feelings that you don't feel comfortable sharing with the whole group, but would like to tell me about. I will not read your comments out loud or share them with any other participant. I will collect your journals at the end of our time together and you will receive a new one next time. If you feel comfortable, please write your name on the journal. You do not need to write your name if you don't want to. 


\section{Focus Group Question Bank (both rounds)}

1. Please introduce yourself, including your grade level and an interesting fact about yourself that you would be willing to share with the group (i.e., hobby, non-school interests, places visited, etc.).

2. What plans do you have for after high school?

3. How do you define success?

4. What does success look like to you? Describe someone who is successful in your life (such as a role model).

5. What are your academic, personal, and career goals? How might you achieve them?

a. What short-term goals have you set for yourself?

b. What long-term goals have you set for yourself?

6. How will you know when you have achieved success?

7. What does your daily life look like?

a. How does your schedule support you in achieving success?

b. How does it create challenges for you in achieving success?

c. What steps do you personally take to help yourself?

d. What is out of your control?

8. What drives you/motivates you to achieve success?

9. What are some pivotal events in your life that have helped you to achieve success?

10. What or who has specifically helped you to achieve success?

11. How does being at CSHS support you in achieving success?

12. What are some examples of how teachers at CSHS have supported you in achieving success?

13. What have your challenges been that have hampered your success?

a. Challenges at CSHS?

b. Challenges outside of CSHS?

14. How have you overcome these challenges?

15. What is missing from CSHS that could better help you achieve success?

16. Have you ever quit or just given up on one of your goals? Why and what happened?

a. Did you get back on track? If so, what helped you to get back on track?

b. If not, what do you think stopped you from getting back on track?

17. How do you define failure for yourself? How do you define failure at school? 
18. What are some of the factors that have led to failure?

19. What strategies or methods do you use to deal with failure?

20. Describe being an African-American/Black or Latino student at CSHS.

21. What impact, if any, has race had on your educational experiences, both positive and negative, here at CSHS? Give an example.

\section{Closure (first round)}

Thank you for participating in today's focus group. I want to remind you that everything shared here today is confidential. It is important that you do not discuss anything with others outside of this group. Last, please take a few minutes to jot down any thoughts or reactions you would like to share with me in the journal I provided. If you feel comfortable, please write your name on the journal. You do not need to write your name if you don't want to. When you are done, place it in this basket here. You will receive a new journal when you return for the second focus group.

\section{Closure (second round)}

Thank you for participating in today's focus group. I want to remind you that everything shared here today is confidential. It is important that you do not discuss anything with others outside of this group. Please take a few minutes to jot down any thoughts or reactions you would like to share with me in the journal I provided. When you are done, place it in this basket here and you are free to go. 


\section{Appendix B}

Recommended Anti-racist Leadership Actions

\begin{tabular}{|c|c|c|}
\hline \multicolumn{3}{|c|}{ Engaging Students and Parents in Community Contexts } \\
\hline Action & Timeframe & $\begin{array}{c}\text { Recommended } \\
\text { Priority Level }\end{array}$ \\
\hline $\begin{array}{l}\text { Build community communication plans } \\
\text { into all action plans at a site, including } \\
\text { site action/improvement plan, school } \\
\text { system development, program } \\
\text { development, course development, etc. }\end{array}$ & Long-term & First \\
\hline $\begin{array}{l}\text { Use district resources to tap into pre- } \\
\text { existing lines of communication (e.g., } \\
\text { communications directors or district- } \\
\text { level minority parent groups) and build } \\
\text { on what is already there. }\end{array}$ & Short-term & Second \\
\hline $\begin{array}{l}\text { Facilitate parent groups for } \\
\text { underrepresented communities. }\end{array}$ & Short-term & Second \\
\hline \multicolumn{3}{|c|}{ Promoting Culturally Responsive and Inclusive School Environments } \\
\hline Action & Timeframe & $\begin{array}{l}\text { Recommended } \\
\text { Priority Level }\end{array}$ \\
\hline $\begin{array}{l}\text { Model a social-justice mind-set in } \\
\text { everyday practices. }\end{array}$ & On-going & First \\
\hline $\begin{array}{l}\text { Develop shared leadership, by building } \\
\text { capacity in others and demonstrating } \\
\text { commitment to anti-racist ideals. }\end{array}$ & On-going & Second \\
\hline $\begin{array}{l}\text { Provide professional development } \\
\text { targeted at racial inequities, privilege, } \\
\text { and bias. }\end{array}$ & On-going & Second \\
\hline $\begin{array}{l}\text { Provide data-driven feedback and } \\
\text { evaluation targeted at racial inequities, } \\
\text { privilege, and bias. }\end{array}$ & On-going & Third \\
\hline
\end{tabular}


Developing Culturally Responsive School Teachers and Curriculum

\begin{tabular}{|c|c|c|}
\hline Action & Timeframe & $\begin{array}{l}\text { Recommended } \\
\text { Priority Level }\end{array}$ \\
\hline $\begin{array}{l}\text { Build a guiding coalition of teacher } \\
\text { leaders to drive the evolution to } \\
\text { Culturally Responsive Education. }\end{array}$ & Short-term & First \\
\hline $\begin{array}{l}\text { Provide time for teacher collaboration } \\
\text { aimed at developing Culturally } \\
\text { Responsive curriculum and instruction. }\end{array}$ & Short-term & Second \\
\hline $\begin{array}{l}\text { Provide professional development to } \\
\text { address inherent biases, deficit-thinking, } \\
\text { and culturally-responsive, research-based } \\
\text { instructional practices and curriculum. }\end{array}$ & On-going & Third \\
\hline $\begin{array}{l}\text { Provide data-driven feedback and } \\
\text { evaluation targeted at racial inequities, } \\
\text { privilege, and bias. }\end{array}$ & On-going & Third \\
\hline $\begin{array}{l}\text { Connect district equity initiatives to the } \\
\text { classroom. }\end{array}$ & $\begin{array}{l}\text { Short- and } \\
\text { long-term }\end{array}$ & Fourth \\
\hline \multicolumn{3}{|c|}{ Critical Self-reflection } \\
\hline Action & Timeframe & $\begin{array}{l}\text { Recommended } \\
\text { Priority Level }\end{array}$ \\
\hline $\begin{array}{l}\text { Develop an inquiry stance to interrogate } \\
\text { own biases and to serve as the foundation } \\
\text { for approaching the construction of } \\
\text { leadership actions. }\end{array}$ & On-going & First \\
\hline $\begin{array}{l}\text { Embed the conversations about race and } \\
\text { privilege into the discourse of the school } \\
\text { and wider community. }\end{array}$ & On-going & Second \\
\hline $\begin{array}{l}\text { Make it a priority to talk with non- } \\
\text { dominate groups of stakeholders. }\end{array}$ & $\begin{array}{l}\text { Short-term } \\
\text { and on- } \\
\text { going }\end{array}$ & Second \\
\hline $\begin{array}{l}\text { Lead staff in vital discussions about race } \\
\text { and privilege. }\end{array}$ & $\begin{array}{l}\text { Short-term } \\
\text { and long- } \\
\text { term }\end{array}$ & Second \\
\hline
\end{tabular}

